\title{
Perspective
}

Subscriber access provided by King Abdullah University of Science and Technology Library

\section{Constructing Bridges between Computational Tools in Heterogeneous and Homogeneous Catalysis}

\author{
Laura Falivene, Sergey M. Kozlov, and Luigi Cavallo \\ ACS Catal., Just Accepted Manuscript • DOI: 10.1021/acscatal.8b00042 • Publication Date (Web): 07 May 2018 \\ Downloaded from http://pubs.acs.org on May 13, 2018
}

\section{Just Accepted}

"Just Accepted" manuscripts have been peer-reviewed and accepted for publication. They are posted online prior to technical editing, formatting for publication and author proofing. The American Chemical Society provides "Just Accepted" as a service to the research community to expedite the dissemination of scientific material as soon as possible after acceptance. "Just Accepted" manuscripts appear in full in PDF format accompanied by an HTML abstract. "Just Accepted" manuscripts have been fully peer reviewed, but should not be considered the official version of record. They are citable by the Digital Object Identifier (DOI®). "Just Accepted" is an optional service offered to authors. Therefore, the "Just Accepted" Web site may not include all articles that will be published in the journal. After a manuscript is technically edited and formatted, it will be removed from the "Just Accepted" Web site and published as an ASAP article. Note that technical editing may introduce minor changes to the manuscript text and/or graphics which could affect content, and all legal disclaimers and ethical guidelines that apply to the journal pertain. ACS cannot be held responsible for errors or consequences arising from the use of information contained in these "Just Accepted" manuscripts. 


\title{
Constructing Bridges between Computational Tools in
}

\section{Heterogeneous and Homogeneous Catalysis}

\author{
Laura Falivene, Sergey M. Kozlov, ${ }^{*}$ Luigi Cavallo* \\ King Abdullah University of Science and Technology (KAUST), \\ KAUST Catalysis Center (KCC), Thuwal 23955-6900, Saudi Arabia.
}

\begin{abstract}
Better catalysts are needed to address numerous challenges faced by humanity. In this perspective, we review concepts and tools in theoretical and computational chemistry that can help to accelerate the rational design of homogeneous and heterogeneous catalysts. In particular, we focus on the following three topics: 1) identification of key intermediates and transition states in a reaction using the energetic span model, 2) disentanglement of factors influencing the relative stability of the key species using energy decomposition analysis and the activation strain model, and 3) discovery of new catalysts using volcano relationships. To facilitate wider use of these techniques across different areas, we illustrate their potentials and pitfalls when applied to the study of homogeneous and heterogeneous catalysts.
\end{abstract}

KEYWORDS: catalysis, computational chemistry, energetic span model, energy decomposition analysis, activation strain model, volcano relationships, rational design, catalyst engineering. 


\section{INTRODUCTION}

In the early decades of the twenty-first century, humanity is facing global challenges related to large increases in the world's population (projected to reach 9.7 billion by 2050 ), ${ }^{1}$ with impacts on energy demands, water resources and food accessibility. Catalysis can contribute to solutions for some of these challenges in environmentally and economically sustainable ways. However, we have only a few decades to develop new or better heterogeneous, homogeneous or bio-catalysts before it is too late to address these challenges. Two main approaches are currently used to develop catalysts. One of them is the well-established "trial-and-error" approach;, other follows the more ambitious "rational design" or "catalyst engineering" paradigm. ${ }^{4,5}$

Although engineering catalysts with desired activity and selectivity sounds appealing, in practice this process requires a detailed understanding of reaction mechanisms ${ }^{6,7}$ to build structure-performance relationships that can be used as guidelines to develop better or new catalysts. Such detailed information is difficult to deduce from experiments, because it involves the characterization of the atomic structures of rare and/or short-lived species, such as reaction intermediates, and the determination of activation barriers by kinetic experiments. ${ }^{8,9}$ At the same time, precise structural information about the considered species is readily available in atomic simulations, which makes computational catalysis a privileged tool for understanding reaction mechanisms ${ }^{10,11}$ and, ultimately, for rational catalyst design. ${ }^{12,13}$

Engineering of highly active catalysts is driven by a few guidelines. In the beginning of the twentieth century, Sabatier formulated the principle that an ideal catalyst for a given reaction should bind the involved reacting species not too strongly and not too weakly. After almost a century of intense research, this principle crystallized in the understanding that an ideal catalyst 
should have a smooth reaction energy profile without a too stable (low-energy) intermediate or without a transition state that is too high in energy. These considerations, which can be applied to any heterogeneous, homogenous or enzymatic catalyst, have spurred the development of a solid theoretical foundation for interpretation of the raw numbers originating from atomic simulations, in a way that leads to rationalization and eventually predictions of catalytic behavior. At the same time, there is a historical gap between computational scientists working on homogeneous catalysis and those working on heterogeneous catalysis due to intrinsic differences between the geometric and electronic structures of the active sites of homogeneous and heterogeneous catalysts. The approaches to catalyst design developed by these two communities have been different, and today the reactivity of homogeneous and heterogeneous catalysts is usually rationalized through different sets of fundamental properties. For example, reactivity of homogeneous catalysts is often described in terms of steric or electronic factors. The former arise from forces (normally non-bonding) between parts of the molecule; the latter capture electronic effects transmitted along the chemical bonds. ${ }^{14}$ Other conceptual schemes popular in homogeneous catalysis involve the analysis of frontier orbitals, such as the energy and shape of the highest occupied and lowest unoccupied molecular orbitals (HOMO-LUMO analysis), the conservation of orbital symmetry, or the isolobal analogy theory. ${ }^{14-16}$ These parameters are mostly considered irrelevant in the reactivity of heterogeneous catalysts, however. Indeed, in heterogeneous catalysis, there are usually no bulky ligands that could cause significant steric repulsion. The energy of the highest occupied electronic state is also usually found to be a suboptimal descriptor of a heterogeneous catalyst's electronic structure. Instead, reactivity of heterogeneous catalysts is described through the position of band centers with respect to the Fermi level ${ }^{17,18}$ or through the binding strength of various atomic species, often $\mathrm{C}$ or $\mathrm{O}$, with the 
catalyst. ${ }^{19,20}$ Naturally, homogeneous catalysts do not have bands and will interact with high-spin single atoms, such as $\mathrm{C}$ or $\mathrm{O}$, in a very peculiar way. These descriptors are thus not very useful for applications in homogenous catalysis.

Nevertheless, in recent years a few computational groups have started to export some of the concepts and tools from homogeneous catalysis to heterogeneous catalysis and vice versa. The scope of this perspective is to highlight these concepts and tools by briefly summarizing their main applications in the original field and then by providing exemplary applications in the other field. As non exhaustive examples, we choose energy decomposition analysis ${ }^{21,22}$ and the energetic span model, ${ }^{23,24}$ developed by the homogeneous catalysis community, as well as the concept of volcano relationships, ${ }^{25,26}$ which has already led to the discovery of several heterogeneous catalysts. We hope that this perspective will foster further efforts to construct bridges connecting the two fields of computational catalysis and that it will stimulate the development of tools to analyze emerging catalytic systems that close the gap between heterogeneous and homogeneous catalysis.

\section{ENERGETIC SPAN MODEL (ESM)}

Catalytic reactions follow mechanisms mostly composed by several steps: the reactants are converted into products through the formation of different intermediates, connected to each other by transition states (Figure 1). 
Figure 1. The catalytic cycle and energy profile of a model reaction. I $=$ intermediates, $\mathrm{TS}=$ transition states.
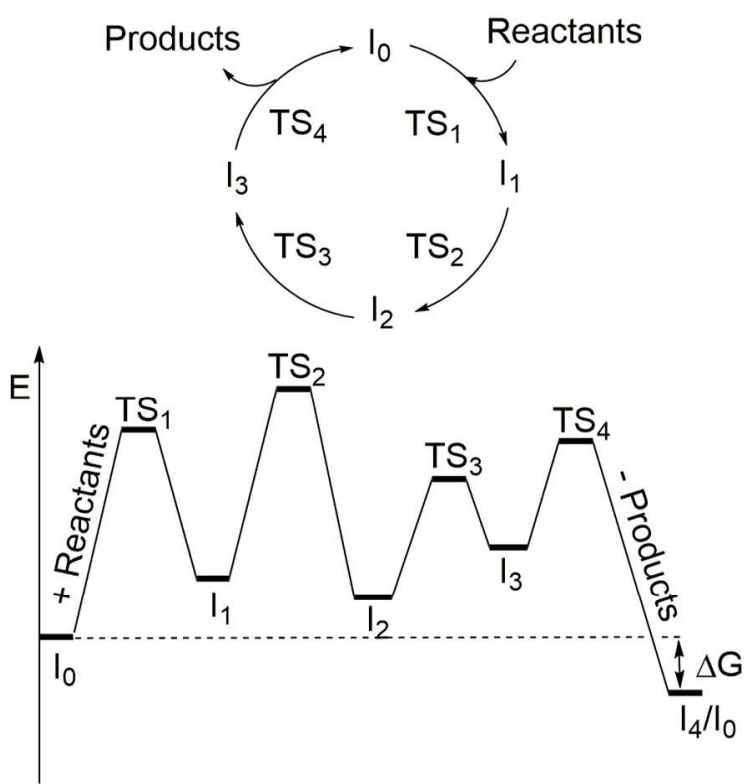

Each catalytic cycle can be translated into an energy profile by reporting the energy of all the species relative to the initial state. To this extent, the reaction will be characterized by a free energy change $(\Delta \mathrm{G})$ that describes the thermochemistry of the reaction from reactants to products, and by the activation barrier $\left(\Delta \mathrm{E}^{\neq}, \Delta \mathrm{G}^{\ddagger}\right)$ for the single reaction step connecting each intermediate to the following transition state. The energetic span model (ESM) is a conceptual tool developed to connect the energy profile derived from electronic-structure calculations to an experimentally accessible quantity, the turnover frequency (TOF). The latter is defined as the number of productive cycles $(\mathrm{N})$ per unit of catalyst $\left[\mathrm{C}_{\mathrm{t}}\right]$ and time $(\mathrm{t})$ as described in Eq. 1:

$$
T O F=\frac{1}{\left[C_{t}\right]} \frac{d N}{d t}
$$


Christiansen described how to derive the TOF from the rate constants of forward and reverse single steps, thereby developing the first kinetic model for catalytic cycles. ${ }^{27}$ Later, Amatore and Jutand ${ }^{28}$ derived the maximum rate of the catalytic cycle $\left(r_{\max }\right)$ and TOF as a function of the total concentration of the catalytic species $\left(\left[C_{t}\right]\right)$, an experimentally known quantity (Eq. 2a-c).

From the Arrhenius rate law, $\mathrm{r}_{\max }$ can be expressed as

$$
r_{\max }=\left[C_{x}\right] A e^{-\frac{\Delta E_{x}^{\neq}}{R T}}
$$

where $\left[C_{x}\right]$ is the concentration of the intermediate preceding the rate-determining transition state and $\Delta E_{x}^{\neq}$is the corresponding energy barrier. Based on the Boltzmann distribution and the assumption that the concentration of all other intermediates is negligible relative to the concentration of the most stable intermediates in the catalytic cycle (the resting state), the concentration of each intermediate can be expressed as a function of the total concentration of the catalyst and of the energy of this intermediate relative to the resting state,

$$
\left[C_{x}\right] \approx\left[C_{t}\right] A e^{-\frac{\Delta E_{x}}{R T}}
$$

When Eq. $2 \mathrm{a}$ and $2 \mathrm{~b}$ are combined, $\mathrm{r}_{\max }$ becomes

$$
r_{\max } \approx\left[C_{t}\right] A e^{-\frac{\left(\Delta E_{x}^{ \pm}+\Delta E_{x}\right)}{R T}}
$$

and the corresponding TOF becomes

$$
T O F=\frac{r_{\max }}{\left[C_{t}\right]} \approx A e^{-\frac{\left(\Delta E_{x}^{\neq}+\Delta E_{\chi}\right)}{R T}}=A e^{-\frac{\delta E}{R T}}
$$

where $\delta \mathrm{E}$ is defined as the energetic span of the cycle, i.e., the energy difference between the points of highest and lowest energy along the reaction profile corresponding to the complete catalytic cycle (Figure 1). 
Eq. $2 \mathrm{~d}$ implies that the smaller the energy span is, the faster the catalysis will be. However, Eq. $2 \mathrm{~d}$ is accurate only under stoichiometric conditions or for reactions at equilibrium, i.e., at $\Delta \mathrm{G}=0$. In fact, in the latter case, the starting point of the second cycle will be at the same energy as for the first cycle and the same equations can be applied.

In 2006, Kozuch and Shaik extended the kinetic model by taking into account the energy balance at the end of the cycle, i.e., the thermochemistry of the reaction, $\Delta \mathrm{G} .{ }^{23,24}$ To evaluate the energy span of the cycle, $\delta E$, they proposed to calculate the energy span, $\delta E_{j k}$, between all transition states $\left(T S_{k}\right)$ and intermediates $\left(I_{j}\right)$ along the catalytic cycle (see Figure 2) as laid out in Eq. 3:

$$
\left\{\begin{array}{lr}
\delta E_{j k}=G\left(T S_{k}\right)-G\left(I_{j}\right) & \text { if } k>j \\
\delta E_{j k}=G\left(T S_{k}\right)-G\left(I_{j}\right)-|\Delta G| & \text { if } k \leq j
\end{array}\right.
$$

In this relation, if $\mathrm{k}>\mathrm{j}$, then $\mathrm{TS}_{\mathrm{k}}$ appears after $\mathrm{I}_{\mathrm{j}}$ in the energy profile (Figure 2a) and $\delta E_{j k}$ is equal to the difference in energy between them; if $\mathrm{k} \leq \mathrm{j}$, then $\mathrm{TS}_{\mathrm{k}}$ appears before $\mathrm{I}_{\mathrm{j}}$ (Figure $2 \mathrm{~b}$ ) and $\delta E_{j k}$ is obtained by subtracting $|\Delta \mathrm{G}|$ from this energy difference. 


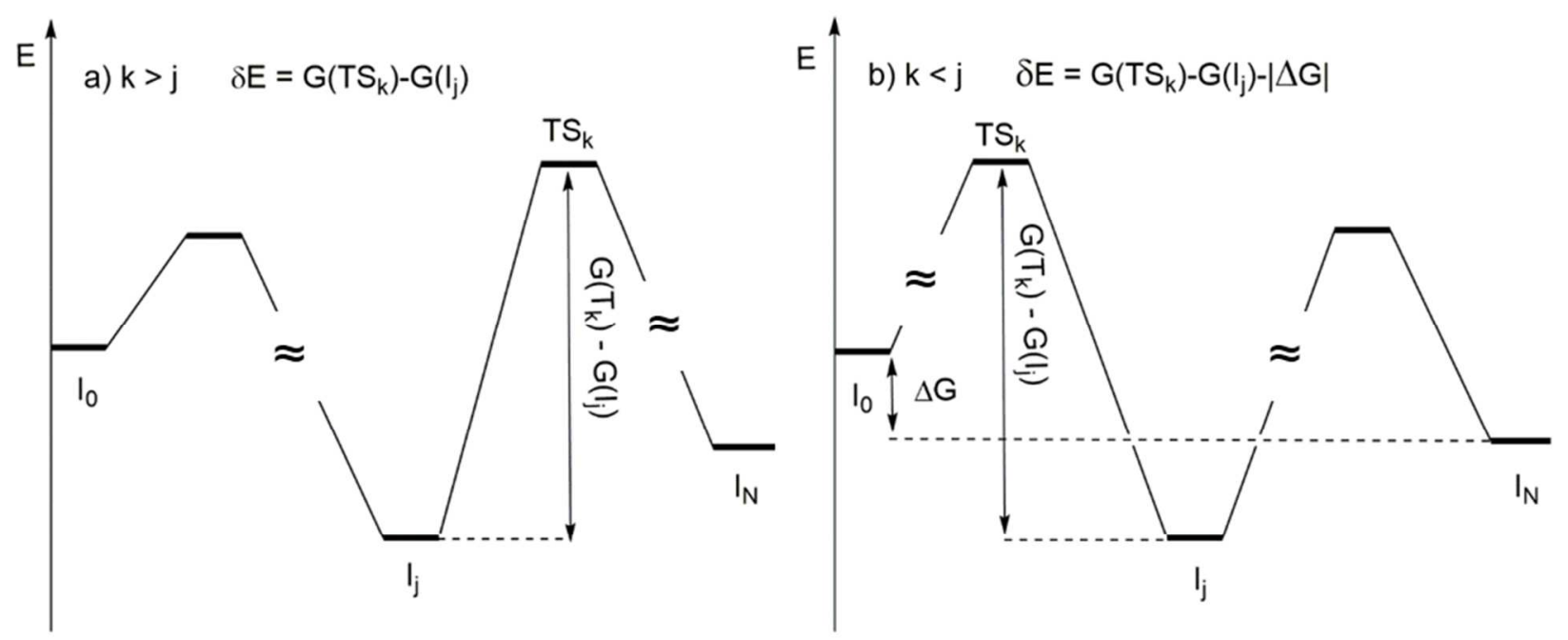

Figure 2. Schematic representation of two scenarios for calculating the energy span. a) The transition state, $\mathrm{TS}_{\mathrm{k}}$, follows intermediate $\mathrm{I}_{\mathrm{j}}$. b) The transition state, $\mathrm{TS}_{\mathrm{k}}$, precedes intermediate $\mathrm{I}_{\mathrm{j}}$.

The highest $\delta E_{j k}$ determined by Eq. 3 is defined as the energy span of the catalytic cycle, $\delta E$, and the corresponding combination of states ( $\mathrm{j}$ and $\mathrm{k}$ ) are defined as the TOF-determining intermediate (TDI) and the TOF-determining transition state (TDTS).

Although this model takes into account the difference in free energy between products and reactants, which is independent of the catalyst, the energy of both intermediates and transition states depends strongly on the catalyst and thus $\delta \mathrm{E}$ depends on the catalyst. Given these dependences, identification of the states defining $\delta \mathrm{E}$, i.e., the TOF-determining states for the reaction, is the key factor in understanding which catalyst features should be changed to reduce $\delta \mathrm{E}$, and thus which catalyst features should be manipulated during the design of new catalysts with higher TOF. If other transition states $\left(\mathrm{TS}_{\mathrm{n}}, ..\right)$ or intermediates $\left(\mathrm{I}_{\mathrm{m}}, ..\right)$ have energies similar to $\mathrm{TS}_{\mathrm{k}}$ or $\mathrm{I}_{\mathrm{j}}$, they should be included in the TOF calculation: ${ }^{24}$

$$
T O F=\frac{1}{1+e^{-b}} A e^{\frac{-\delta E}{R T}}
$$




$$
b=\left(T S_{k}-I_{j}\{-\Delta G\}\right)-\left(T S_{n}-I_{m}\{-\Delta G\}\right)
$$

As consequence of this reformulation, the TOF will be lowered by increasing the number of combinations between extreme intermediates and transition states with similar energies in the cycle to the point that it will be halved if there are two combinations of states yielding the same $\delta \mathrm{E}$. In any case, a fundamental consequence of ESM is the clarification that neither one reaction step nor one transition state possesses all the kinetic information to determine the efficiency of a catalyst. Technically speaking, great accuracy in the calculation of the energetic profile is required to obtain a precise and trustworthy TOF value that can be compared with experimental results.

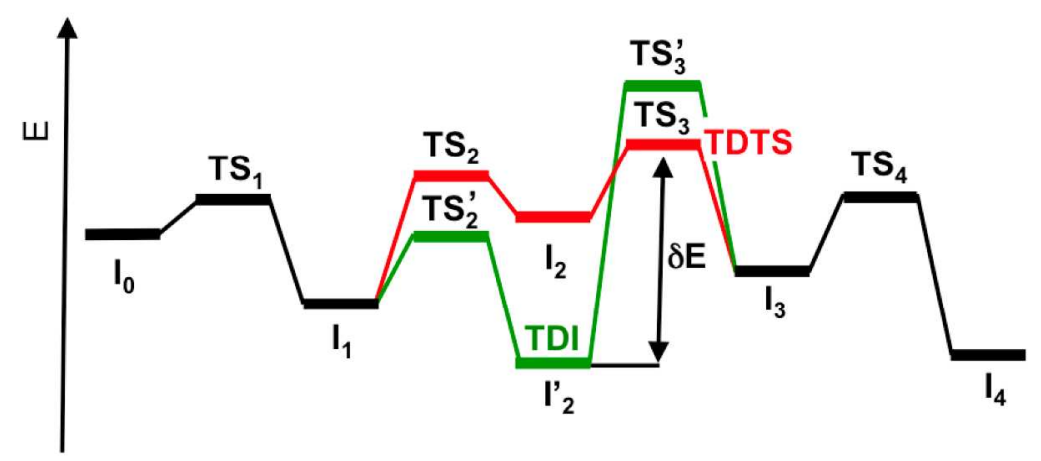

Figure 3. In the case of two competing reaction pathways (red and green lines), TDI may be from one pathway and TDTS from another. Reproduced with permission from Ref. 29.

In addition, the correct calculation of the energetic span for a given reaction may require calculating several feasible reaction pathways to assemble the operative one. Indeed, TDI and TDTS are the pair of states that maximize the energy span value within the operative reaction pathway. For example, analysis of the energy profile of Figure 3 indicates that the thermodynamic sink of the catalytic cycle is intermediate $I_{2}$ on the red pathway. However, the most likely evolution of this intermediate toward products does not occur via the high energy 
transition state $\mathrm{TS}_{3}$. Rather, it occurs via reverse conversion of $\mathrm{I}_{2}{ }_{2}$ to $\mathrm{I}_{1}$, followed by evolution of $\mathrm{I}_{1}$ to products via transition state $\mathrm{TS}_{3}$, which is the TDTS, as indicated in Figure 3.

In the field of homogeneous catalysis, ESM has been successfully applied to a large number of different transition-metal catalyzed reactions including cross-coupling, ${ }^{30-32}$ hydrogenation, ${ }^{33,34}$ hydrosilylation, amination, ${ }^{35}$ cycloaddition, ${ }^{36}$ and olefin metathesis. ${ }^{37,38}$ In the following, we describe exemplary applications of the model to demonstrate its capabilities to discern alternative mechanistic hypotheses and to provide new insights into the factors that control the catalytic cycle.

Application of ESM in homogeneous computational catalysis started with Shaik's pioneering work on transition-metal catalyzed cross-coupling reactions. Even though the basic mechanism of this reaction consists of only three generic steps, i.e., oxidative addition, transmetallation or substitution, and reductive elimination, many factors (metal identity, ligand landscape, an organo-reagent coupling partner involved in the transmetallation step, etc.) can play key roles in determining the efficiency of the catalytic cycle and, especially, the identity of the ratedetermining states.

For example, let us consider the cross-coupling between an anhydride and an organozinc compound catalyzed by a nickel bipyridyl complex reported by Martin. ${ }^{31}$ Experimental results revealed that the rate of the reaction had first-order dependency on the catalyst concentration and zero-order dependency on the anhydride concentration. The span model allowed the observed kinetics to be rationalized, highlighting the crucial importance of identifying the rate-determining states. $^{29,31}$ 


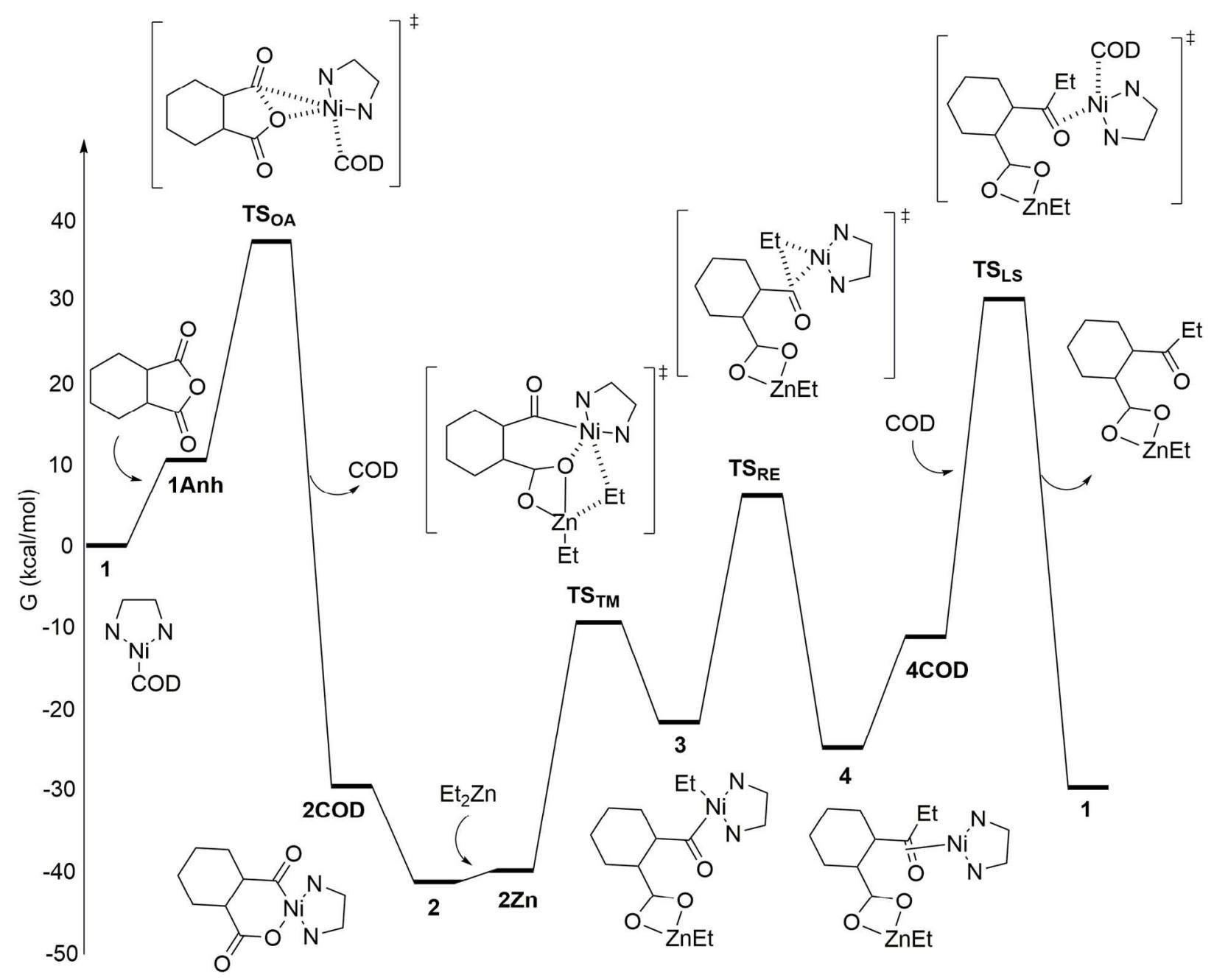

Figure 4. Computed free energy profiles versus the reaction coordinate of the full Ni cycle. Reproduced with permission from Ref. 31.

The full energetic profile shown in Figure 4 depicts the low-energy pathway connecting the reactant species, i.e. the anhydride and the organozinc compound, to the coupling product. The first transition state, represented by the oxidative addition of anhydride to nickel $\left(\mathbf{T S}_{\mathbf{O A}}\right)$ is the free-energy maximum of the whole catalytic cycle; the corresponding product is the free energy minimum ( 2 in Figure 4). The identification of TDI is straightforward since it coincides with the lowest-energy species; on the contrary, the identification of TDTS requires careful analysis of the reaction profile. In fact, defining TS $_{\mathbf{O A}}$ as TDTS based on its absolute energy is incorrect. 
Since TDI comes after $\mathbf{T S}_{\mathbf{O A}}$, the corresponding energy span is calculated as $\delta \mathrm{E}=\mathrm{G}\left(\mathbf{T} \mathbf{S}_{\mathbf{L S}}\right)-$ $\mathrm{G}(2)-\Delta \mathrm{G}_{\mathrm{rx}}$, where $\Delta \mathrm{G}_{\mathrm{rx}}$ is the overall change in the free energy of the reaction (Figure 4) according to Eq. 3. On the contrary, the last TS of the cycle, the ligand substitution TS $\left(\mathbf{T S}_{\mathbf{L S}}\right.$ ), appears after TDI, with the corresponding energy span simply calculated as the difference in free energy, $\delta \mathrm{E}=\mathrm{G}\left(\mathbf{T S}_{\mathbf{L S}}\right)-\mathrm{G}(\mathbf{2})$. The combination of states $\mathbf{2}$ and $\mathbf{T S}_{\mathbf{L S}}$ in Figure 4 maximizes $\delta \mathrm{E}$, indicating that the ligand substitution is the TDTS of the cycle. Identifying the two TOFdetermining states makes possible affirmation that the rate of the reaction depends only on the catalyst concentration and that no dependency from the anhydride concentration should be expected (since no free anhydride is involved in TDI and TDTS), in agreement with experimental results. In sum, ESM allowed the authors to rationalize the intriguing dependencies of the reaction rate on the concentration of the reagents and to identify the two critical species of the cycle, thus providing the basis for the possible design of better performing catalysts.

Kozuch and Martin exploited the span model to rationalize the experimentally observed ${ }^{39}$ inefficiency of the $\mathrm{Pd}$ catalyst bearing the $\mathrm{PMe}_{3}$ ligand instead of the larger $\mathrm{PPh}_{3}$ and $\mathrm{PtBu}_{3}$ ones in the Suzuki-Miyaura cross-coupling reaction. They derived the turnover number (TON) by including the formation of intermediates along deactivation pathways in the analysis. ${ }^{40}$ As TON is a measure of the expected life time of a catalyst, it can be calculated from the energetic span and the energy barrier for deactivation (see ${ }^{40}$ for further details):

$$
T O N \approx e^{\frac{\left(-\delta E+T S_{d}-I_{x}\right)}{R T}}
$$

When the catalyst includes the small phosphine $\mathrm{PMe}_{3}$, the catalyst can precipitate into a very stable trans-diphosphine species outside the catalytic cycle. The TON calculated by taking into account the formation of this trans-diphosphine species explains the basically nonexistent activity of this catalyst, even though it has quite a good TOF. 
ESM also quantitatively describes how important each intermediate and transition state is to the reaction rate. In early papers, the degree of rate control, $X$, was defined as the normalized influence of a rate constant on the overall reaction rate when all other rate and equilibrium constants remained constant. ${ }^{41}$ Within the framework of ESM, this quantity is redefined for a given state along the catalytic cycle as follows:

$$
X_{T O F, i}=\left|\frac{1}{T O F} \frac{\partial T O F}{\partial E_{i}}\right|
$$

The larger $X_{\text {TOF }}$ is, the higher the influence of the corresponding state on the TOF. Li et al. calculated $X_{T O F}$ for each species participating in the lanthanum-catalyzed bicyclooligomerization of acetylene to naphthalene. ${ }^{42}$ Their reported mechanism consists of more than 24 states among intermediates and transition states. The calculation of $X_{\text {TOF }}$ allowed them to easily recognize TDI and TDTS, given that these states are the ones that maximize $\delta \mathrm{E}$, i.e., they have an $X_{\text {TOF }}$ close to one.

Similarly, Wang et al. referred to the calculation of $X_{T O F}$ and $\delta \mathrm{E}$ to rationalize the activity and the enantioselectivity of [4+3] cycloaddition between vinylcarbenoids and dienes catalyzed by rhodium complexes. ${ }^{43}$ Using ESM, they not only identified TDI and TDTS in a complex mechanistic scenario, but they also rationalized the effect of substitution on the $X_{T O F}$ of the different species and, consequently, on the stereoselectivity of the reaction.

Until now, reactions occurring on heterogeneous catalysts have been seldom analyzed using ESM, although this possibility was initially suggested by Kozuch and Shaik. ${ }^{44}$ Namely, they used ESM to analyze the $\mathrm{N}_{2}+3 \mathrm{H}_{2} \leftrightarrow 2 \mathrm{NH}_{3}$ reaction under various conditions to explain why different catalysts are needed for $\mathrm{NH}_{3}$ synthesis and decomposition. However, to perform such analysis the authors had to use "gross" simplifications for the reasons outlined below. 
Unlike homogeneous catalysts, heterogeneous catalysts expose a variety of active sites commonly located in the vicinity of each other. Moreover, even the simplest reactions may require several active sites to be present close to each other to proceed, e.g., dissociative adsorption of hydrogen, nitrogen or oxygen, $\mathrm{A}_{2}+2^{*} \rightarrow 2 \mathrm{~A}^{*}$, where * indicates a surface site available for adsorption or an already adsorbed species. This requirement greatly complicates the kinetics of surface reactions involving $\mathrm{O}_{2}$ dissociation, such as CO oxidation. ${ }^{45,46}$ Naturally, these complications are not taken into account in ESM, which provides a realistic description for only single-site reactions. ${ }^{47}$ Thus, ESM cannot be used for precise modeling of the kinetics of reactions involving heterogeneous catalysts.

The second reason why ESM has not been widely used in heterogeneous catalysis is that it ultimately leads to the calculation of TOF, which is difficult to measure in heterogeneous catalysis. As mentioned before, heterogeneous catalysts often contain a multitude of various surface sites and it is difficult to determine how many of these sites are actually catalytically active. The activity of a catalyst per active site is rarely ever measured. Rather, catalytic activity is typically reported per surface area ${ }^{48}$ However, when experimental TOF can be measured, it can be easily converted into experimental energy span values, as was done for $\mathrm{H}_{2} \mathrm{O}_{2}$ decomposition promoted by $\mathrm{Fe}^{2+}$ ions in $\alpha-\mathrm{Fe}_{2} \mathrm{O}_{3} \cdot{ }^{49}$ Moreover, simulations of heterogeneous catalysts are almost always performed on simplified catalyst models, e.g., infinite perfect periodic single crystal surfaces, whereas real catalysts are typically composed of catalyst nanoparticles attached to mesoporous support materials. This discrepancy further limits the degree of quantitative agreement between experimental and computational results. Finally, when TDTS is not previously identified, ESM requires precisely calculated energies of all the transition states in the reaction energy profile. Obtaining transition states on heterogeneous 
catalysts seems to be significantly more difficult than in molecular systems. The difficulty in calculating transition states in computational heterogeneous catalysis contributes to the limited application of ESM in this field.

Nevertheless, for many reactions, the complicated nature of surface kinetics as well as the complicated morphology of real heterogeneous catalysts can be neglected for practical purposes. Indeed, quantitative results from experiments and simulations often differ, although they follow very similar qualitative trends. Rational design and discovery of new catalysts in silico relies mostly on trends in catalytic activity, rather than on precise values. This discovery process is often done using simplified "thermodynamic" volcano relationships constructed for perfect single crystal surfaces (see Section 4).

Apart from some fundamental studies of cluster reactivity, ${ }^{50,51}$ ESM is mostly used in computational heterogeneous catalysis studies to simplify the analysis of the competing reaction pathways with complicated energy profiles. A critical advantage of ESM is that it can be used as a "black-box" tool without any ad-hoc adjustments, allowing researchers to focus on the chemistry of the system. For example, ESM led to the conclusion that ethylene oligomerization on Ni-containing SSZ-24 zeolite proceeds via the Cossee-Arlman mechanism, instead of via metallacycle or proton transfer mechanisms. ${ }^{52}$ This analysis also revealed that the TDI in the former mechanism is not the intermediate with the lowest energy.

Knowing the most probable reaction pathway is important because this pathway governs the selectivity of a catalyst. For example, the analysis of various transformations of furfural on a $\operatorname{Pd}(111)$ surface using ESM allowed the rationalization of the change in catalytic selectivity from furan at low $\mathrm{H}$ coverage to fufuryl alcohol at high $\mathrm{H}$ coverage.$^{53}$ As well, the higher selectivity of $\mathrm{Rh}(111)$ towards 1,2-pentanediol than towards 1,5-pentanediol and 2-methyltetrahydrofuran in 
the transformation of tetrahydrofurfuryl alcohol was rationalized by comparing the respective energy spans. $^{54}$

To further showcase both the potentials and pitfalls of ESM when applied to computational heterogeneous catalysis, we used it to analyze some already published reaction energy profiles. First, we considered work on a simplified scheme describing dry reforming of methane (DRM):

$$
\mathrm{CH}_{4}+\mathrm{CO}_{2} \rightarrow 2 \mathrm{CO}+2 \mathrm{H}_{2}
$$

on $\mathrm{Ni}(111) .{ }^{55}$ Based on simulations, it was argued that the elementary step of methane activation,

$$
\mathrm{CH}_{4} \rightarrow \mathrm{CH}_{3}^{*}+\mathrm{H}^{*}
$$

has the highest activation energy of $1.17 \mathrm{eV}$ and should be considered as the rate-limiting step in this reaction, if desorption of products is not considered (Figure 5). ${ }^{55}$ This conclusion was in contrast to the common belief that elemental $\mathrm{C}$ formation,

$$
\mathrm{CH}^{*} \rightarrow \mathrm{C}^{*}+\mathrm{H}^{*},
$$

could be the rate-limiting step. ESM revealed that neither of these processes considered in Ref. 55 determines the reaction rate. Rather, it indicates that TDTS is the C-O bond formation (TS31 in Figure 5) via

$$
\mathrm{CH}^{*}+\mathrm{O}^{*} \rightarrow \mathrm{CHO}^{*}
$$

whose energy with respect to the initial state is $0.91 \mathrm{eV}$. At the same time, two intermediate configurations, $\mathrm{CO}^{*}+\mathrm{O}^{*}+\mathrm{CH}_{4}$ and $\mathrm{CO}^{*}+\mathrm{O}^{*}+\mathrm{CH}^{*}+3 \mathrm{H}^{*}$, have similarly low energies approximately equal to $-0.7 \mathrm{eV}$, and therefore have to be considered as TDI. Here, ESM leads us to two important conclusions. First, the resulting energetic span of $\delta \mathrm{E} \approx 1.6 \mathrm{eV}$ is significantly higher than the activation energies of methane activation or elemental carbon formation. Second, ESM shows that the elementary step of $\mathrm{CH}$ oxidation is not, in fact, rate limiting. Indeed, if $\mathrm{CH}^{*}$ 
binding to the catalyst had been weaker, then $\mathrm{CO}^{*}+\mathrm{O}^{*}+\mathrm{CH}_{4}$ would become the sole TDI and the reaction rate would not critically change.

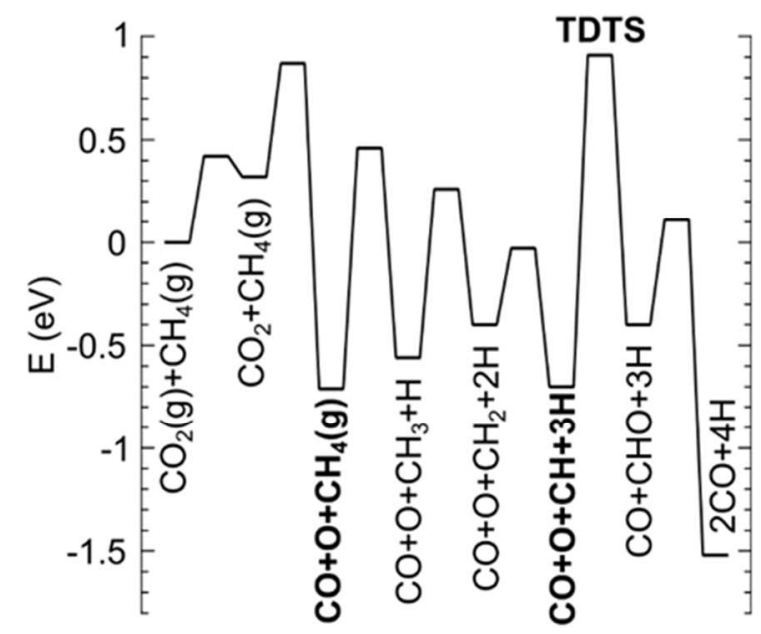

Figure 5. Simplified reaction energy profile of dry reforming of methane on $\mathrm{Ni}(111)$ based on data in Ref. 55. The TOF-determining intermediates are $\mathrm{CO}^{*}+\mathrm{O}^{*}+\mathrm{CH}_{4}(\mathrm{~g})$ and $\mathrm{CO}^{*}+\mathrm{O}^{*}+\mathrm{CH}^{*}+3 \mathrm{H}^{*}$; the TOF-determining transition state is $\mathrm{CH}^{*}+\mathrm{O}^{*} \rightarrow \mathrm{CHO}^{*}$.

Due to the previously mentioned limitations, application of the ESM to reactions on heterogeneous catalysts, particularly when approximating a multi-site reaction by a single-site process, should be done carefully. To illustrate such complications, we consider methanol synthesis from $\mathrm{CO}_{2}$ on ceria clusters supported on $\mathrm{Cu}(111)$ single-crystals. ${ }^{56}$ The TDTS in this reaction is unambiguously TS5 (Figure 6) corresponding to

$$
\mathrm{CO}^{*}+\mathrm{H}^{*}+\left[\mathrm{H}^{*}+\mathrm{H}_{2}(\mathrm{~g})+\mathrm{H}_{2} \mathrm{O}(\mathrm{g})\right] \rightarrow \mathrm{HCO}^{*}+\left[\mathrm{H}^{*}+\mathrm{H}_{2}(\mathrm{~g})+\mathrm{H}_{2} \mathrm{O}(\mathrm{g})\right]
$$

where $\mathrm{E}(\mathrm{TDTS}) \approx-0.25 \mathrm{eV}$. We can also consider two intermediate configurations, $\mathrm{CO}_{2}{ }^{*}+2 \mathrm{H}^{*}$ $+2 \mathrm{H}_{2}(\mathrm{~g})$ and $\mathrm{CO}^{*}+\mathrm{H}_{2} \mathrm{O}^{*}+2 \mathrm{H}^{*}+\mathrm{H}_{2}(\mathrm{~g})$, as TOF-determining intermediates with very similar energies of $\mathrm{E}(\mathrm{TDI}) \approx-1.2 \mathrm{eV}$. The differences between these two intermediate states are partially caused by the

$$
\mathrm{H}_{2}(\mathrm{~g}) \rightarrow 2 \mathrm{H}^{*}
$$

and 


$$
\mathrm{H}^{*}+\mathrm{OH}^{*} \rightarrow \mathrm{H}_{2} \mathrm{O}^{*}
$$

reactions occurring alongside the considered transformations of $\mathrm{CO}_{2}$. Importantly, these two side reactions occur independently on other sites. They therefore do not belong to the considered catalytic cycle, which can be simplified to

$$
\begin{gathered}
\mathrm{CO}_{2}+* \rightarrow \mathrm{CO}_{2}^{*} \stackrel{+H^{*}}{\longrightarrow} \mathrm{OCOH}^{*} \stackrel{+H^{*}-\mathrm{H}_{2} \mathrm{O}^{*}}{\longrightarrow} \mathrm{CO}^{*} \stackrel{+H^{*}}{\longrightarrow} \mathrm{HCO}^{*} \stackrel{+H^{*}}{\longrightarrow} \\
\mathrm{H}_{2} \mathrm{CO}^{*} \stackrel{+H^{*}}{\longrightarrow} \mathrm{H}_{3} \mathrm{CO}^{*} \stackrel{+H^{*}}{\longrightarrow} \mathrm{H}_{3} \mathrm{COH}^{*} \stackrel{+H^{*}}{\longrightarrow} \mathrm{H}_{3} \mathrm{COH}+* .
\end{gathered}
$$

The contributions of the mentioned side reactions (Figure 6),

$$
\Delta \mathrm{E}\left[\mathrm{H}_{2}(\mathrm{~g}) \rightarrow 2 \mathrm{H}^{*}\right] \approx 0.7 \mathrm{eV} \text { and } \Delta \mathrm{E}\left[\mathrm{H}^{*}+\mathrm{OH}^{*} \rightarrow \mathrm{H}_{2} \mathrm{O}^{*}\right] \approx 0
$$

should therefore not be included in the energetic span analysis, although they were included in the reaction energy profile. Upon excluding the contributions of the side reactions to the energies in Figure 6, the energetic span for the first intermediate becomes

$$
\begin{gathered}
\delta \mathrm{E}=\mathrm{E}[\mathrm{TDTS}]-\mathrm{E}\left[\mathrm{CO}_{2}^{*}+2 \mathrm{H}^{*}+2 \mathrm{H}_{2}(\mathrm{~g})\right]-\Delta \mathrm{E}\left[\mathrm{H}_{2}(\mathrm{~g}) \rightarrow 2 \mathrm{H}^{*}\right]- \\
\Delta \mathrm{E}\left[\mathrm{H}^{*}+\mathrm{OH}^{*} \rightarrow \mathrm{H}_{2} \mathrm{O}^{*}\right] \approx-0.25+1.2+0.7-0 \mathrm{eV} \approx 1.65 \mathrm{eV}
\end{gathered}
$$

In turn, the second identified intermediate does not require such corrections, and its $\delta \mathrm{E}$ value is therefore smaller:

$$
\delta \mathrm{E} \approx-0.25+1.2 \mathrm{eV} \approx 0.95 \mathrm{eV} .
$$

Thus, TDTS of methanol synthesis from $\mathrm{CO}_{2}$ corresponds to the

$$
\mathrm{CO}^{*}+\mathrm{H}^{*} \rightarrow \mathrm{HCO}^{*}
$$

process, whereas TDI is the adsorbed $\mathrm{CO}_{2}{ }^{*}$ species.

As shown above, the application of the ESM to heterogeneous catalysis requires careful separation between the main catalytic cycle and the side reactions occurring on other sites. The characteristic feature in identifying such side reactions is that they do not have a fixed place in the reaction sequence. For example, dissociative adsorption of $\mathrm{H}_{2}$ can be moved to the beginning 
of the considered reaction energy profile and water formation to its end without changing the main catalytic process.
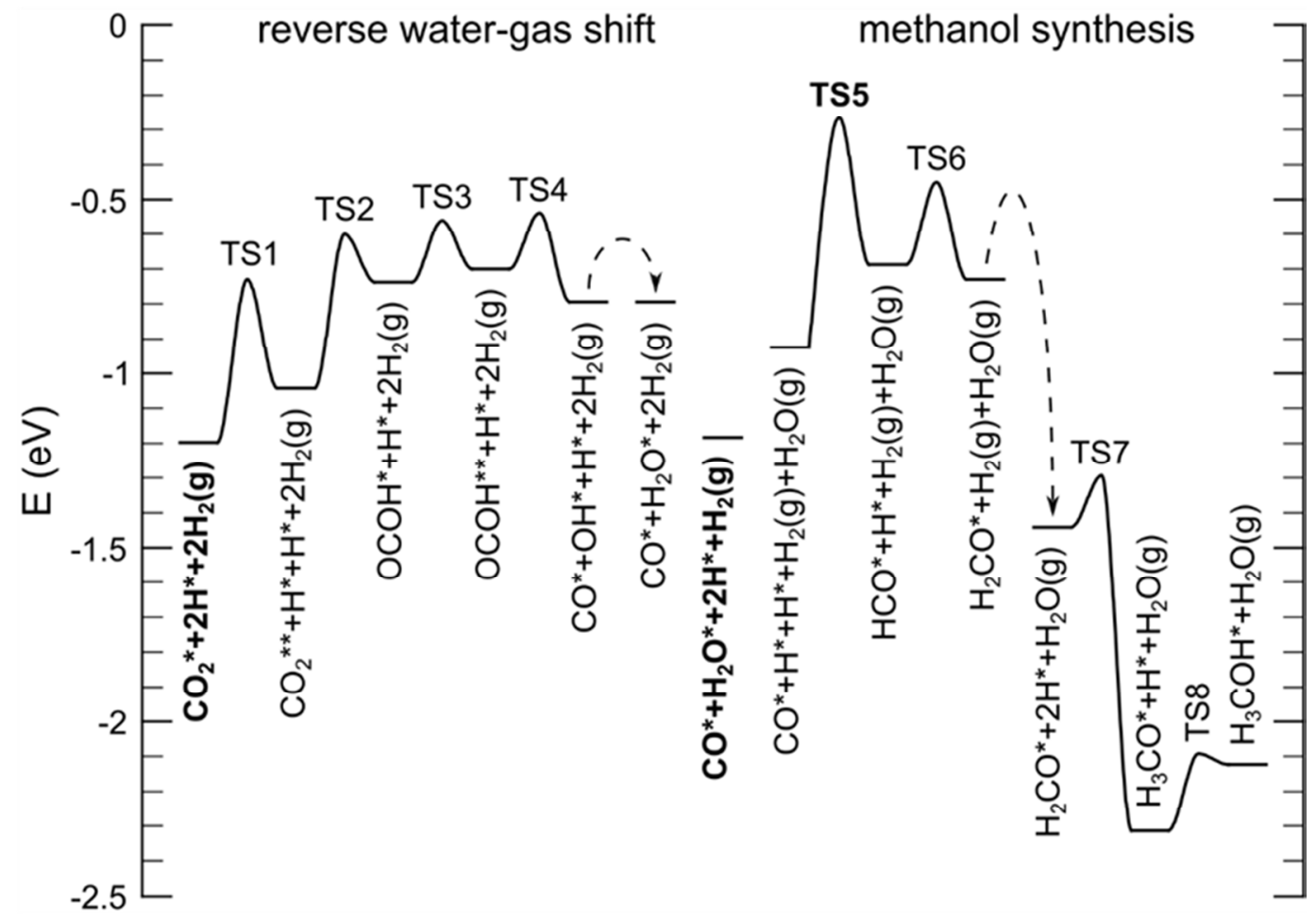

Figure 6. Simplified reaction energy profile of $\mathrm{CO}_{2}$ hydrogenation to methanol on $\mathrm{CeO}_{\mathrm{x}} / \mathrm{Cu}(111)$ based on data from Ref. 56 with adsorbed species marked by “*” sign. Key intermediate and transition states are highlighted in bold, dashed arrows indicate the elementary steps of $\mathrm{OH}^{*}+\mathrm{H}^{*} \rightarrow \mathrm{H}_{2} \mathrm{O}^{*}$ and $\mathrm{H}_{2}(\mathrm{~g}) \rightarrow 2 \mathrm{H}^{*}$.

\section{ENERGY DECOMPOSITION ANALYSIS AND THE ACTIVATION STRAIN MODEL (ASM)}

In the previous section, we described a rigorous approach to identifying the rate-determining steps along a reaction pathway and to determining how the expected TOF of a given catalyst can be related to the energy span of the reaction. One way to engineer catalysts is to reduce the energy span by either destabilizing a too stable intermediate or by stabilizing a too high-energy transition state. To do so, it is important to have access to tools that can deconstruct the energy of the TOF-determining species. Since the introduction of molecular orbital theory, attempts to 
rationalize reactivity in terms of orbital interactions became widespread. Among the most noted examples are Woodward-Hoffmann rules, ${ }^{57,58}$ Fukui's frontier molecular orbital theory, ${ }^{59}$ and Marcus theory. ${ }^{60}$ Here, we focus on a model that explains reactivity on the basis of both geometrical properties and bonding capabilities of reacting species. This energy decomposition scheme was initially developed by Morokuma $^{21}$ and Ziegler and Rauk to analyze equilibrium structures. It can be straightforwardly used to describe the overall interaction energy of any two fragments, $\mathrm{A}$ and $\mathrm{B}$, forming an A-B complex. The simplest version of this energy decomposition scheme assumes that the total interaction energy, $\mathrm{E}_{\text {Tot }}$ in Figure 7 , can be decomposed into deformation energy, $\mathrm{E}_{\mathrm{Def}}$ (also referred to as distortion or preparation energy in the literature), and interaction energy, $E_{\text {Int }}$ (Figure 7). $E_{\text {Def }}$ is the cost in energy to deform interacting fragments from their optimal geometries to the geometries they will have upon interaction. In turn, $\mathrm{E}_{\mathrm{Int}}$ is the interaction energy between the deformed fragments. By definition, $E_{\text {Def }}$ is positive and destabilizing, whereas $E_{\text {Int }}$ is negative and stabilizing. $E_{\text {Int }}$ can be further decomposed into other energy components with physical meaning, ${ }^{21,22}$ but these components are beyond the scope of this perspective.

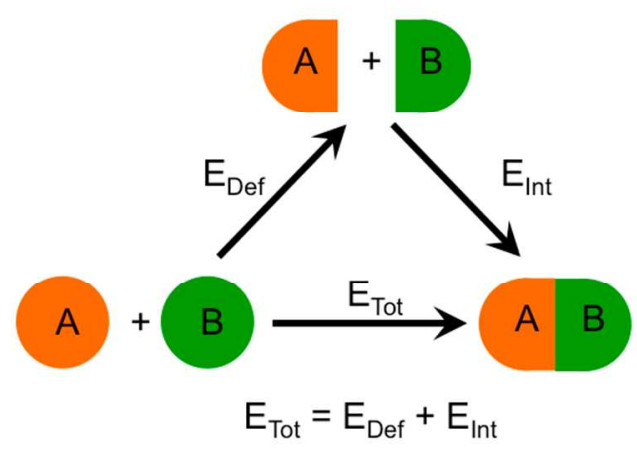

Figure 7. Schematic representation of various contributions to total energy. 
This energy decomposition analysis scheme has broad applicability in catalysis, from the study of the coordination energy of a molecule to a metal complex or to the surface of a heterogeneous catalyst, to the analysis of the activation energy of a particular elementary step. The extension of energy decomposition analysis to transition states was initially proposed by Morokuma $^{61}$ and Houk ${ }^{62}$ to analyze transition-state geometries in organic reactions. This method was further refined by several groups ${ }^{62-64}$ into the model known today as the distortion/interaction or the activation strain model (ASM). ${ }^{65}$

The idea at the foundation of these approaches is that the height of reaction barriers, $\Delta E^{\neq}$, can be decomposed as

$$
\Delta E^{\neq}=\Delta E_{\text {Strain }}^{\neq}+\Delta E_{\text {Int }}^{\neq}
$$

where $\Delta E_{\text {Strain }}^{\neq}$and $\Delta E_{\text {Int }}^{\neq}$are the differences between the $\mathrm{E}_{\text {Def }}$ and $\mathrm{E}_{\text {Int }}$ values calculated for an intermediate and the following transition state (Figure 7). $\Delta E_{\text {Strain }}^{\neq}$is mostly impacted by the strength of the bonds in the substrate involved in the catalytic event (stronger bonds lead to larger $\Delta E_{\text {Strain }}^{\neq}$), the rigidity of the reacting fragments, and any kind of structural/conformational reorganization of the reacting fragments occurring in the transition state. $\Delta E_{I n t}^{\neq}$depends on the electronic structure of the reactants and on the proper orientation of the reacting fragments as they approach each other (the larger overlap and closer proximity in the energy between the frontier orbitals of the two fragments lead to more favorable $\left.\Delta E_{\text {Int }}^{\neq}\right)$. Bickelhaupt ${ }^{65,66}$ expanded this decomposition model to the whole reaction pathway, i.e., from reactants to products including transition states, by choosing an appropriate reaction coordinate, $\xi$ (e.g., a crucial bond distance), and calculating $\Delta E_{\text {Strain }}^{\neq}$and $\Delta E_{I n t}^{\neq}$as the reaction coordinate changes. In homogeneous catalysis, ASM is mainly used to analyze transition states and to rationalize the 
origin of a given reaction barrier and eventually to predict the structures of new or improved catalysts. $^{67-69}$

A prototype application of ASM is the study of the activation of the carbon-halogen bond by Pd. This reaction can occur via an oxidative-addition (OA) pathway that retains the configuration of the $\mathrm{C}$ atom, or via a $\mathrm{S}_{\mathrm{N}} 2$-type pathway inverting the configuration of the $\mathrm{C}$ atom (see Figure 8$).^{70-72}$

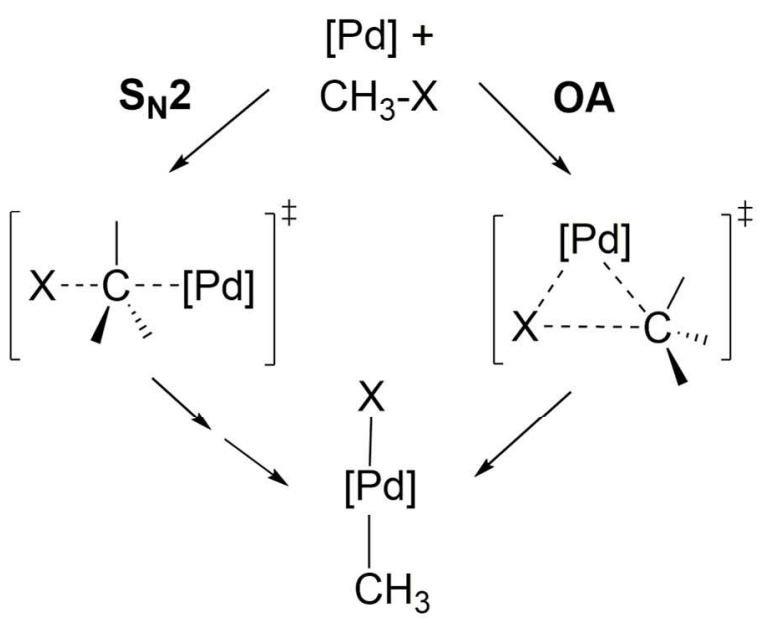

Figure 8. Schematic representation of $\mathrm{OA}$ and $\mathrm{S}_{\mathrm{N}} 2$ mechanisms for the activation of a R-X bond by Pd.

Standard electronic structure calculations indicated that activation of halomethanes by $\mathrm{Pd}$ is easier with heavier halogens in both the $\mathrm{OA}$ and $\mathrm{S}_{\mathrm{N}} 2$ pathways. ${ }^{70-72}$ These calculations also confirmed the experimental result that in the presence of a naked Pd atom, the OA pathway is favored, whereas when the chloride coordinated to the $\mathrm{Pd}$, i.e., when $\mathrm{PdCl}^{-}$is considered as a catalyst, the $\mathrm{S}_{\mathrm{N}} 2$ pathway is favored. ASM was used to deconstruct this switch in the preferred reaction pathway.

ASM analysis applied to both the starting Pd-halomethane complex and to the OA transition state revealed that the change in the strength of the Pd-halomethane interaction in the starting 
complex follows the halogen electronegativity trend. ${ }^{70-72}$ This happens because the energy of the empty $\sigma^{*}$ molecular orbital corresponding to the carbon-halogen bond decreases along the group, reducing the energy gap with the filled orbitals of Pd. ASM analysis of the transition state revealed that the strain energy is governed by the stretch of the carbon-halogen bond from its length at equilibrium to its length in the transition state. As a consequence, the strain energy follows the change in the strength of the carbon-halogen bond, with the highest energy penalty corresponding to the stronger $\mathrm{H}_{3} \mathrm{C}-\mathrm{F}$ bond. Comparisons between the interaction energy and the strain energy indicated that the energy barriers are dominated by the strain energy, which explains the correlation of the energy barrier with the carbon-halogen bond energy.

ASM analysis of the $\mathrm{S}_{\mathrm{N}} 2$ pathway revealed that the strain energy is significantly higher than that in the OA pathway due to greater distortion of the halomethane geometry in the transition state. This increase in the strain energy is not compensated by a similar increase in the interaction energy and the OA pathway is thus favored. Coordinating a $\mathrm{Cl}^{-}$to the $\mathrm{Pd}$ atom, which means using $\mathrm{PdCl}^{-}$as the catalyst, has little impact on the strain energy, while it significantly increases the interaction energy in the $\mathrm{S}_{\mathrm{N}} 2$ transition state. This increase in the interaction energy was calculated to be large enough to counterbalance the strain energy along the $\mathrm{S}_{\mathrm{N}} 2$ pathway and to switch the reactivity from the $\mathrm{OA}$ to the $\mathrm{S}_{\mathrm{N}} 2$ pathway. In a similar way, the strain model helped to explain the trend in activity in the model $\mathrm{S}_{\mathrm{N}} 2$ reaction of $\mathrm{Cl}^{-}$with $\mathrm{RCl}$, where $\mathrm{R}$ $=\mathrm{CH}_{3}, \mathrm{NH}_{2}, \mathrm{OH}$, or $\mathrm{F}^{73}$ The stabilizing interaction energy increases with the electronegativity of the $\mathrm{R}$ group due to the lower energy of the unoccupied acceptor orbital, i.e., a stronger HOMO-LUMO orbital interaction, and the geometric strain has only a minimal contribution on the overall activation barrier. 
The examples presented above show the potential of ASM to rationalize experimentally observed behaviors. The model can also be used to predict and guide experimental efforts. This is illustrated by recent work on OA of aryl-halide bonds to $\mathrm{Au}(\mathrm{I})$ complexes, leading to $\mathrm{Au}(\mathrm{III})(\operatorname{aryl})($ halide) complexes, which is a difficult reaction to achieve, compared with the facile OA of aryl-halides to $\mathrm{Pd}(0) .{ }^{74}$ Bickelhaupt showed that the energy barrier for OA of aryl-halides to $\mathrm{Au}(\mathrm{I})$ catalysts based on a linear L-Au-L geometry is due to the energy penalty associated with deformation of the linear framework into a bent framework (see Figure 9 ). ${ }^{75}$ At the same time, Au(I) complexes containing chelating diphosphines with small bite angles, thus already deformed towards the bent geometry that they will assume in the oxidative addition transition state/product, perform $\mathrm{OA}$ of phenyl iodide to $\mathrm{Au}(\mathrm{I})$ at low temperature..$^{76,77}$

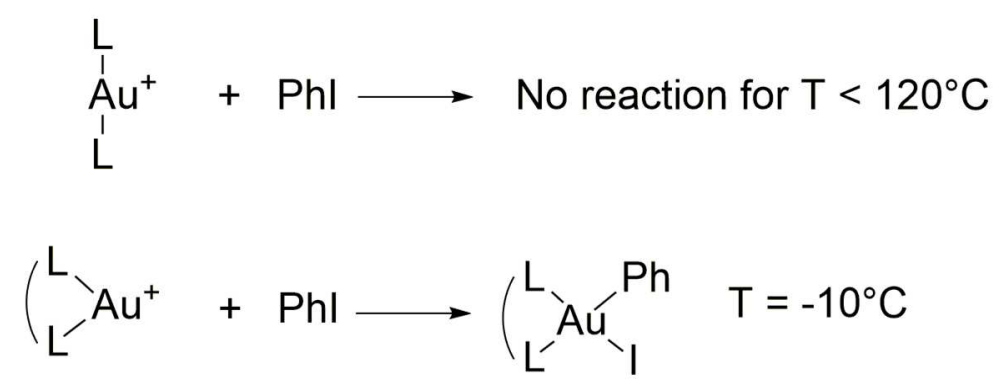

Figure 9. Observed reactivity for Au catalyzed by $\mathrm{PhI} \mathrm{OA}$ in relation to the ligand framework. $\mathrm{L}=$ ligand (e.g., phosphine, $\mathrm{PR}_{3}$ )

Another prototype example of the application of ASM to guide experimental work is in the analysis of the evolution of the strain and interaction energies from the reactant to the transition state geometry. This analysis was particularly useful to rationalize the lower activation barrier for the hydrogenation of unsaturated $\mathrm{C}=\mathrm{X}$ bonds $(\mathrm{X}=$ heteroatom $)$ relative to $\mathrm{C}=\mathrm{C}$ bonds using the ruthenium Noyori hydrogenation catalyst (see Figure 10). ${ }^{78}$ 


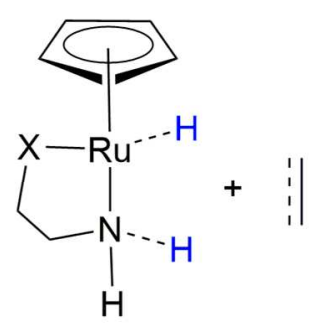

Figure 10. ASM for the Noyori hydrogenation reaction. Reproduced with permission from Ref. 78.
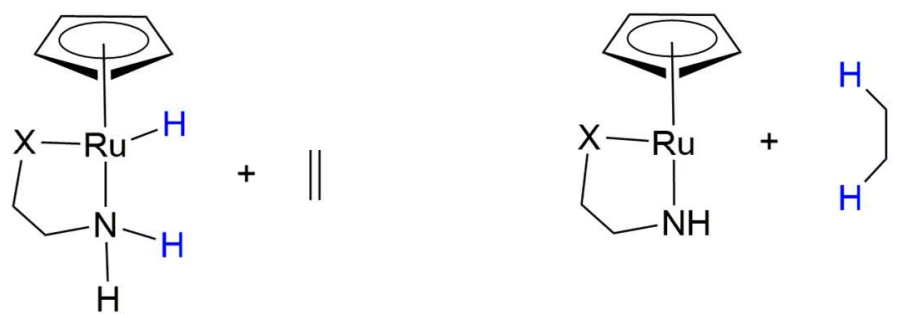

Using ethylene and formaldehyde as model systems, the ASM analysis reported in Figure 11 shows that the strain energy (red curve) similarly increases for both species, whereas the interaction energies (blue curves) significantly differ. The interaction energy for ethylene increases up to $\mathrm{H} \cdots \mathrm{C}$ distances of approximately $1.8 \AA$ (Figure $11 \mathrm{a}$ ), due to the repulsion between filled orbitals on the two fragments. On the contrary, with formaldehyde (Figure 11b), the interaction energy is always stabilizing due to the formation of an intramolecular hydrogen bond between the $\mathrm{NH}$ group of the catalyst and the heteroatom. The stabilization provided by 
this interaction term compensates for the strain energy and the reaction proceeds with a considerably lower reaction barrier.
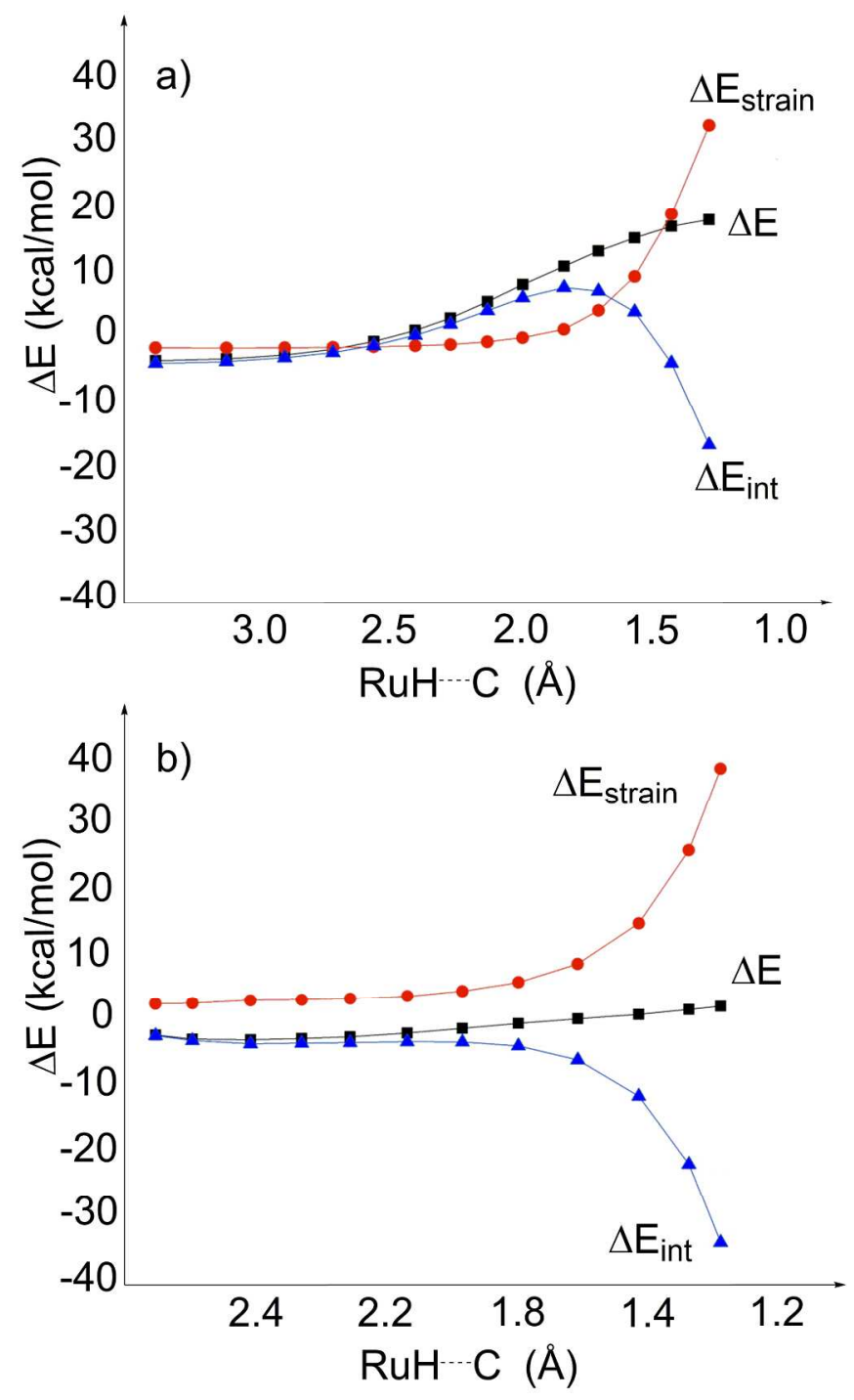

Figure 11. a) ASM analysis of the Noyori hydrogenation reaction involving ethylene and b) formaldehyde. Reproduced with permission from Ref. 78.

ASM has mostly been used to deconstruct energy barriers in homogeneous catalysis, since localization of transition states in heterogeneous catalysis is not yet routine. Nevertheless, 
implementation of better algorithms for transition-state localization, together with more easily available computational power, is making localization of transition state geometries in heterogeneous catalysis more common, which has stimulated the use of ASM to rationalize activation barriers of reactions involving heterogeneous catalysts. Aleksandrov et al. investigated alkyl hydrogenation on Pd (111) surfaces and on Pd nanoparticles (Figure 12). ${ }^{79}$

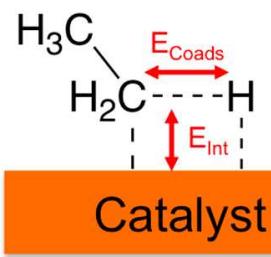

Figure 12. Scheme used to analyze ethyl hydrogenation promoted by Pd catalysts. ${ }^{79} \mathrm{E}_{\text {Coads }}$ accounts for the interaction energy between the ethyl group and the hydrogen, while $\mathrm{E}_{\text {Int }}$ accounts for the interaction between the Pd catalyst and the reacting fragments.

The activation energy barrier was decomposed as in Eq. 8:

$$
\Delta E^{\neq}=\Delta E_{\text {Int }}^{\neq}+\Delta E_{\text {Def }, \text { Adsorbate }}^{\neq}+\Delta E_{\text {Def,Surf }}^{\neq}+\Delta E_{\text {Coads }}^{\neq}
$$

where $\Delta E_{\text {Def,Adsorbate }}^{\neq}$and $\Delta E_{\text {Def,Surf }}^{\neq}$are the deformation energies of the ethyl and $\mathrm{Pd}$ fragments from the reactants to the transition states, $\Delta E_{I n t}^{\neq}$accounts for the interaction between the $\mathrm{Pd}$ catalysts and the reacting fragments, and $\Delta E_{\text {Coads }}^{\neq}$accounts for the interaction energy between the alkyl group and the hydrogen. Within this definition, $\Delta E_{\text {Int }}^{\neq}$is positive (which is at odds with the convention in homogeneous catalysis), since the interaction between the reacting fragments and the Pd catalyst decreases as the forming alkane detaches from the Pd surface in the transition state. Consistency between Eq. 7 and standard usage in homogeneous catalysis is restored if the total interaction energy driving the reaction is considered as $\Delta E_{\text {Int }}^{\neq}+\Delta E_{\text {Coads }}^{\neq}$. Aleksandrov et al. preferred to keep the two contributions separate to isolate the metal-fragment 
interaction in $\Delta E_{\text {Int }}^{\neq}$and to derive chemical insights that could be correlated with the experimental behavior. This case demonstrates the natural difficulties in establishing unique conventions between heterogeneous and homogeneous catalysis.

In this case, the deformation (strain) terms turned out to be not significant and, interestingly, they were going in opposite directions for the surface and the reactant molecules. $\Delta E_{\text {Def,Surf }}^{\neq}$stabilizes the transition state since the $\mathrm{Pd}$ nanoparticle is more relaxed in the transition state, where forming ethane is almost desorbed, than in the initial state, where the ethyl and hydrogen fragments are adsorbed. In turn, the deformation of ethyl is stronger in the transition state due to a five-coordinated $\mathrm{C}$ atom interacting both with the $\mathrm{Pd}$ catalyst and the $\mathrm{H}$ atom. The interaction energy between the surface and the adsorbates is of course stronger in the initial state than in the transition state, where the forming $\mathrm{C}_{2} \mathrm{H}_{6}$ molecule starts to detach from Pd. Aleksandrov et al. correlated this with the impact of hydrogen loading on the studied barrier. When the content of hydrogen increases and subsurface hydrogen begins to be present in the nanoparticle, the catalyst-adsorbate interaction becomes weaker in the starting material, leading to a reduction of approximately $20 \mathrm{~kJ} / \mathrm{mol}$ in the overall barrier.

As stated above, ASM was initially developed to analyze equilibrium structures. ${ }^{21,22}$ To this extent, the thermodynamics of adsorbate-catalyst complex formation can be analyzed in terms of the interplay between stabilizing and destabilizing forces, as in the analysis of the activation energy of a reaction. This approach has broadened the applicability of ASM to heterogeneous catalysis, as equilibrium structures can be easily obtained with computational tools. For example, Sautet et al. analyzed the adsorption energy of benzene to different sites of the Pd (111) surface, $E_{a d s}$, using Eq. 9:

$$
E_{a d s}=E_{a d s, I n t}+E_{a d s, D e f}
$$


where $E_{a d s, I n t}$ and $E_{a d s, D e f}$ are the equivalent of $\Delta E_{\text {Int }}^{\#}$ and $\left(\Delta E_{\text {Def,Adsorbate }}^{\#}+\Delta E_{\text {Def,Surf }}^{\#}\right)$ in the barrier terms. ${ }^{80}$ This analysis indicated a strong interaction, $E_{a d s, \text { Int }}$, between benzene and the Pd (111) surface (from -1 to $-2.5 \mathrm{eV}$ depending on the adsorption site), with deformation of the benzene geometry upon coordination resulting in a sizeable destabilizing term (from +0.5 to +1.5 eV depending on the adsorption site, see Figure 13). The deformation energy of the surface was shown to be negligible. This study allowed Sautet et al. to explain why the bridge adsorption site (see Figure 13a) with the molecule showing the largest distorted structure (see Figure 13b) corresponds to the strongest adsorption energy. Distortion of benzene enhances the interaction between the electronic states of benzene and the electronic states of the metal near the Fermi level. The carbon atoms of the distorted benzene acquire a partial $\mathrm{sp}^{3}$ character thereby reducing the aromaticity. This distortion increases the HOMO energy and decreases the LUMO energy (see Figure 13b), allowing stronger interactions with the vacant and filled electronic states of the metal. 
a)
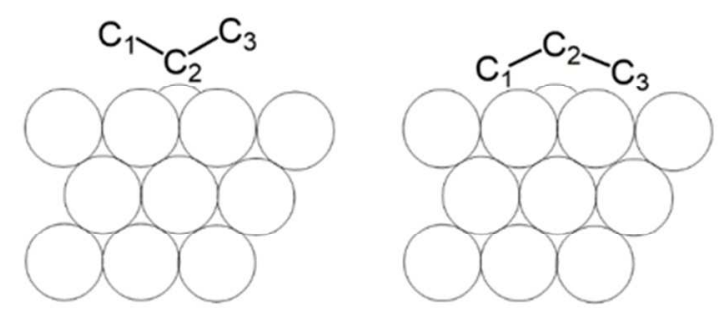

b)<smiles>c1ccccc1</smiles>

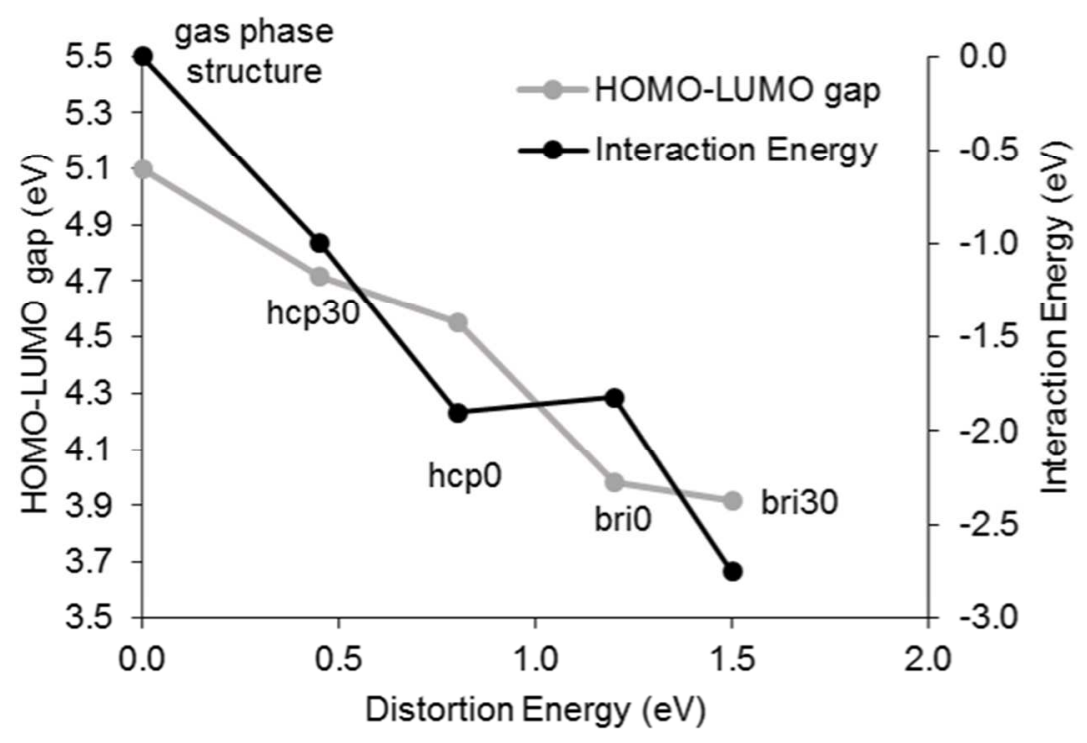

Figure 13. a) Geometries of benzene chemisorbed on $\operatorname{Pt}(111)$ on a bridge site and an hcp site. c) HOMO-LUMO benzene orbital energy gap and interaction energy between the molecule and the surface as a function of the molecular distortion energy. Adapted with permission from Ref. 80 .

This scheme was also used to explain the stronger adsorption of benzene on $\mathrm{Pt}$ and $\mathrm{Rh}$, compared with that on $\mathrm{Pd}$. Larger deformation of benzene on $\mathrm{Pt}$ and $\mathrm{Rh}$ results in the lowering of the benzene HOMO-LUMO gap, resulting in a stronger interaction with the electronic states of Pt and Rh and thus in larger adsorption energies. ${ }^{81}$

This approach proved to be particularly useful in rationalizing the lower adsorption energy of alkenes on Pt-Sn alloys compared with pure Pt. ${ }^{82,83}$ Adsorption energies, $\mathrm{E}_{\text {ads, }}$, decrease on the alloy although the geometries and the hybridization of the alkenes are similar to those calculated 
for the pure Pt system. Thus, the interaction of the alkene with $\mathrm{Pt}, \mathrm{E}_{\mathrm{int}}$, is only slightly favored relative to that with the Pt-Sn alloy (see Table 1). The main difference between Pt and Pt-Sn is in the energy cost related to the modification of the surface, $\mathrm{E}_{\mathrm{Def}, \text { Surf. }}$ Alkene coordination requires the formation of a $\mathrm{Pt}$ dimer that slightly protrudes from the surface. The energy cost for the optimal deformation of the surface was shown to be higher for the alloy, resulting in a decrease in the overall adsorption energy. The importance of the surface deformation energy in determining the adsorption energy, as highlighted by energy decomposition analysis, was further confirmed in a series of other alloys, ${ }^{84,85}$ suggesting that surface deformation energy is another important factor in determining the reactivity of alloys, besides the well-known shift of the dband center upon alloying. ${ }^{18,86}$ In fact, the d-band center is a property of the catalyst alone, while the higher energy cost to deform the alloy is a consequence of the catalyst-adsorbate interaction. The magnitude of the surface deformation and its contribution to the binding energy therefore depends on the specific adsorbate considered, an observation in agreement with experimental behavior.

Table 1. Energy contributions for an adsorbed ethane and cyclopentene molecule in $\mathrm{kcal} / \mathrm{mol}$. Adapted with permission from Ref. 84.

\begin{tabular}{cccccc}
\hline & $\mathrm{C}_{2} \mathrm{H}_{4}$ & & & $\mathrm{C}_{5} \mathrm{H}_{8}$ & \\
\hline $\mathrm{Pt}$ & $\mathrm{Pt}_{3} \mathrm{Sn}$ & $\mathrm{Pt}_{2} \mathrm{Sn}$ & $\mathrm{Pt}$ & $\mathrm{Pt}_{3} \mathrm{Sn}$ & $\mathrm{Pt}_{2} \mathrm{Sn}$ \\
\hline-24 & -16 & -14 & -22 & -10 & -7 \\
4 & 8 & 12 & 4 & 11 & 15 \\
33 & 34 & 35 & 36 & 37 & 36 \\
-61 & -58 & -60 & -61 & -58 & -59 \\
\hline
\end{tabular}

While the work cited above indicated that the energy required to deform the surface can play a relevant role when different catalysts are considered, other studies indicated that the 
deformation energy of the adsorbate also plays a major role, as demonstrated in the binding energy of $\mathrm{C}_{2} \mathrm{H}_{\mathrm{x}}(\mathrm{x}=0-4)$ species to (111) surface of Pd, Pt, Rh and Ni. ${ }^{87}$ As reported in Figure 14a, the adsorption energy of acetylene does not follow the trend that a decrease in the amount of $\mathrm{H}$ in the molecule corresponds to a stronger interaction. This could be easily explained via energy decomposition analysis, which indicates a large and out-of-trend deformation energy for acetylene adsorption (see Figure 14b) compared with a more regular trend in the interaction energy (see Figure 14c). 
a)

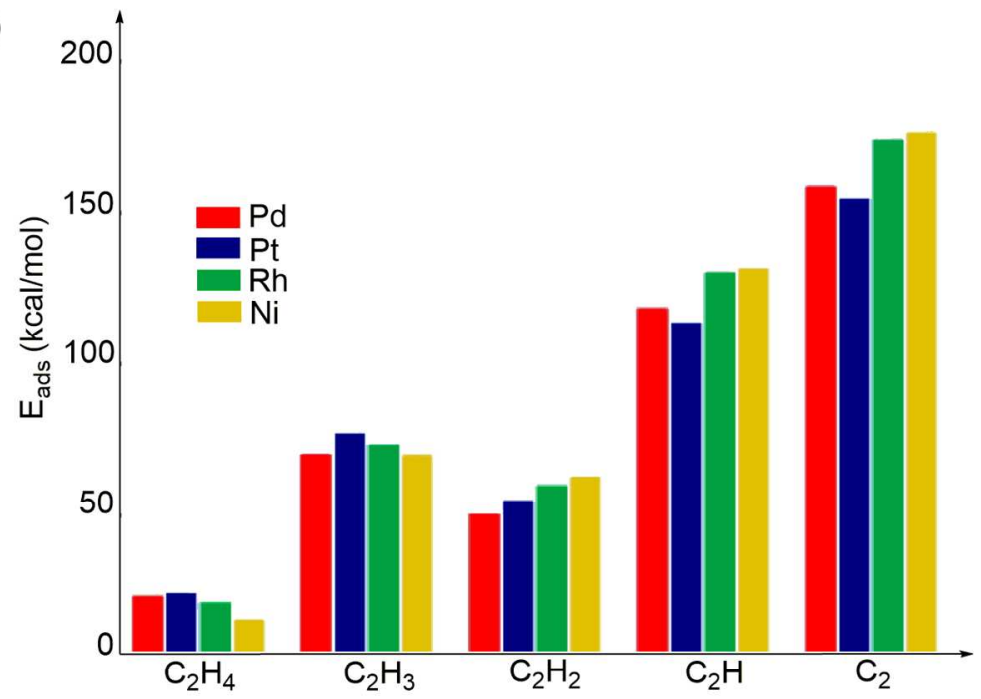

b)

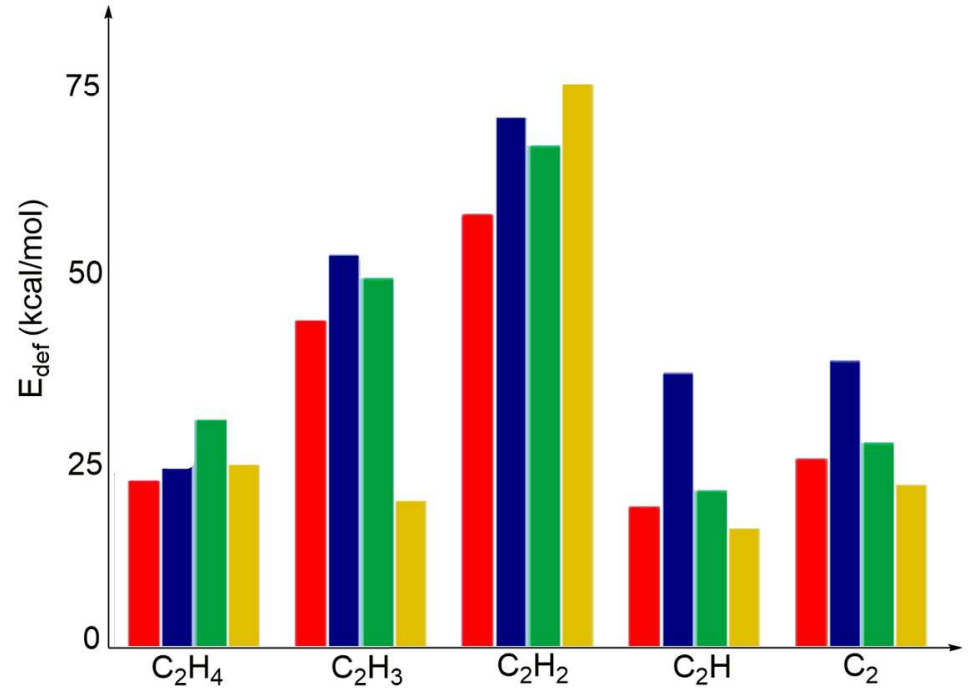

c)

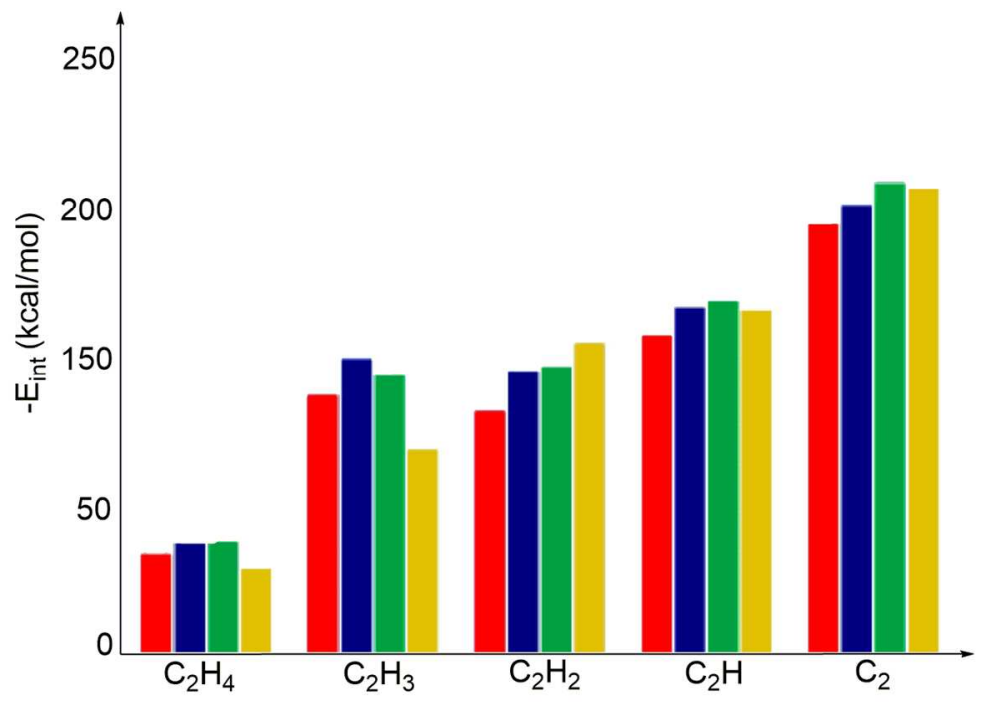


Figure 14. a) Adsorption, b) interaction and c) deformation energies for adsorption of $\mathrm{C}_{2} \mathrm{H}_{\mathrm{x}}(\mathrm{x}=$ 0-4) species on different (111) surfaces. Adapted with permission from Ref. 87.

\section{VOLCANO RELATIONSHIP}

Sabatier formulated the famous principle that an ideal catalyst for a given reaction should bind the involved reacting species not too strongly and not too weakly. This principle implies that catalytic activity has a volcano-like dependency on the growing binding strength of a catalyst: first it increases as the reactants become more easily activated, then reaches its peak and finally decreases as it becomes harder for products to detach from the catalyst (the so called "volcano relationship"). However, it took almost a century of research to reach this conclusion in the present form and to understand the fundamental chemistry underlying it. $^{25}$

One of the first reactions analyzed from this perspective was the electrochemical hydrogen evolution reaction (HER),

$$
\mathrm{H}^{+}+\mathrm{e}^{-} \rightarrow \mathrm{H}^{*} \rightarrow 1 / 2 \mathrm{H}_{2}
$$

where “*” indicates the species adsorbed on the catalyst's surface. Early experimental investigations in 1920s and 1930s attempted to construct relationships between HER activity and various properties of catalysts, such as the position in the periodic table, melting temperature and work function. ${ }^{88,89}$ Horiuti and Polanyi were among the first to realize that HER activity is governed by the binding strength of $\mathrm{H}^{*}$ to the catalyst ${ }^{90,91}$ and that, for practical purposes, the binding of the other involved species (solvated protons or molecular hydrogen) can be safely neglected. The volcano relationship between the binding of $\mathrm{H}^{*}$ and HER activity was understood only in 1950s through the analysis of the pertinent kinetic equations. ${ }^{92}$ Because the binding strength of $\mathrm{H}^{*}$ to the catalytically active sites was impossible to measure until the mid-1970s, Trasatti $^{93}$ used hydride formation energies to construct the volcano relationship. 
In the 1980s, Trasatti reported a similar volcano relationship (Figure 15) between "the enthalpy of lower $\rightarrow$ higher oxide transition" and the activity of a catalyst in the oxygen evolution reaction (OER), assuming a one-site mechanism ${ }^{94}$ :

$$
\mathrm{H}_{2} \mathrm{O} \stackrel{-e^{-}-H^{+}}{\longrightarrow} \mathrm{OH}^{*} \stackrel{-e^{-}-H^{+}}{\longrightarrow} \mathrm{O}^{*} \stackrel{+H_{2} O-e^{-}-H^{+}}{\longrightarrow} \mathrm{OOH}^{*} \stackrel{-e^{-}-H^{+}}{\longrightarrow} \mathrm{O}_{2} .
$$

The empirical volcano relationship for OER was discovered even though the reaction involves multiple intermediates strongly interacting with the catalyst, unlike in the simpler case of HER. In the 1990s, the volcano relationship for OER was also derived from kinetic equations after the realization that mechanisms of both HER and OER are governed by electron and proton transfer steps. ${ }^{95}$ Soon, the application of volcano relationships to study OER was extended to alloys of Pt. $^{96,97}$

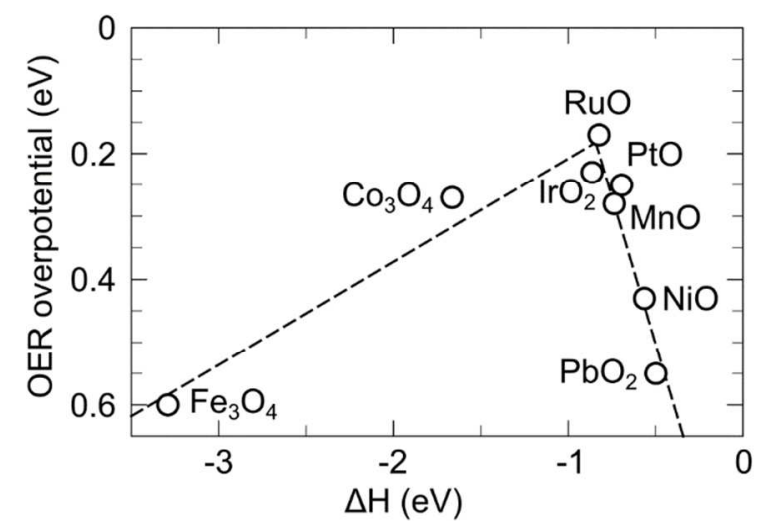

Figure 15. OER overpotential on various oxides in acid plotted as a function of the enthalpy of the transition from a lower to a higher oxidation state, $\Delta \mathrm{H}$, adapted from Ref. 94 with permission from Elsevier.

In this and many subsequent studies, the electrochemical activity of a catalyst is characterized by its overpotential, $\eta=\mathrm{V}-\mathrm{V}_{\text {eq. }}$. Here, $\mathrm{V}_{\text {eq }}=\Delta \mathrm{G} / \mathrm{q}$ is the equilibrium potential defined by the energy of the half-reaction, $\Delta \mathrm{G}$, and the amount of transferred charge, $\mathrm{q}$, which captures the thermodynamic limitations of the half-reaction. In turn, $\mathrm{V}$ is the electrode potential required for a half-reaction to proceed on the given catalyst and it differs from $V_{\text {eq }}$ due to the kinetics of the 
catalyzed half-reaction. Experimentally, $\mathrm{V}$ is usually measured as the electrode potential when the current density reaches $\mathrm{j}=10 \mathrm{~mA} / \mathrm{cm}^{2}$. Computationally, $\mathrm{V}_{\text {eq }}$ is usually defined as the electrode potential that makes the reaction energy of each elementary step of the overall halfreaction non-positive, $\Delta \mathrm{G}_{\mathrm{i}} \leq 0$, which is usually in line with experimental values. ${ }^{26,98}$ With this definition, the overpotential is positive in oxidation half-reactions, negative in reduction halfreactions (sometimes positive values are reported for both cases) and zero for an ideal catalyst.

The development of volcano relationships in the twentieth century was sluggish because the binding energies of various species to catalysts, the key element in the relationships, were largely unavailable. Even now, binding energies remain very difficult to measure. Empirically constructed volcano relationships therefore continue to rely on other descriptors of catalytic activity. Such descriptors often reflect the electronic structure of the material, which is known to ultimately govern its chemical properties. For example, there are known empirical volcano relationships between the activity of Pt alloys in the oxygen reduction reaction (ORR):

$$
\mathrm{O}_{2} \stackrel{+e^{-}+H^{+}}{\longrightarrow} \mathrm{OOH}^{*} \stackrel{+e^{-}+H^{+}-\mathrm{H}_{2} \mathrm{O}}{\longrightarrow} \mathrm{O}^{*} \stackrel{+e^{-}+H^{+}}{\longrightarrow} \mathrm{OH}^{*} \stackrel{+e^{-}+H^{+}}{\longrightarrow} \mathrm{H}_{2} \mathrm{O}
$$

and the positions of their d-band centers ${ }^{99}$ as well as between the OER activity of perovskites and the occupancy of $e_{g}$ electronic states. ${ }^{100}$

In the beginning of the twenty-first century, electronic structure methods became powerful and reliable enough to provide sufficiently accurate binding energies of various species to catalysts. This development triggered a revolution in heterogeneous catalysis, providing the first versatile framework for the rational design of catalysts in silico. ${ }^{26}$ Recently, this approach was combined with the degree of rate control concept (see Section 5), ${ }^{41,101}$ which could make computational catalyst screening even more efficient. ${ }^{102}$ 
Volcano relationships were combined with electronic structure calculations for the first time in a study rationalizing the high activity of Co-Mo alloys in ammonia synthesis. ${ }^{103}$ According to the volcano relationship, Co binds $\mathrm{N}$ too weakly to be a perfect catalyst, whereas Mo binds $\mathrm{N}$ too strongly. However, their alloy was calculated to have an N-binding strength that puts the catalyst at the top of the volcano. The concept that a better catalyst can be obtained by alloying two metals that are located on opposite sides of the volcano has led to the rational design and discovery of numerous catalysts. For example, Fe dissociatively adsorbs $\mathrm{CO}$ too strongly for $\mathrm{CO}$ methanation and $\mathrm{Ni}$ adsorbs $\mathrm{CO}$ too weakly, while Fe-Ni alloys feature an intermediate binding strength and are significantly better catalysts for this reaction. ${ }^{104}$

Another example comes from HER in which highly active Pt catalysts can be improved by alloying Pt with a poorly performing HER catalyst, Bi. ${ }^{105}$ The latter performs poorly in HER because the $\mathrm{H}^{*}$ energy is $0.8 \mathrm{eV}$ higher than that of $1 / 2 \mathrm{H}_{2}$, whereas it should be exactly the same in an ideal catalyst. At the same time, $\mathrm{Pt}$ is one of the best HER catalysts because the $\mathrm{H}^{*}$ energy is only $\sim 0.1 \mathrm{eV}$ lower than that of $1 / 2 \mathrm{H}_{2} .{ }^{106}$ As a result, the Pt-Bi alloy displays almost perfect $\mathrm{H}$ binding strength and is more active than pure Pt in HER. For HER, the volcano relationships between the experimental catalytic activity and the calculated H-binding energies have been presented for transition-metal ${ }^{106}$ and phosphide catalysts. ${ }^{107}$ Even the activities of nitrogenase and hydrogenase enzymes can be correlated to their suitable energy of $\mathrm{H}$ binding. ${ }^{108}$ This observation has led to the discovery of HER activity of $\mathrm{MoS}_{2}$ edges, whose structure resembles the active sites in these enzymes. ${ }^{108}$ On the other hand, there are still some disagreements between calculated and experimental activation energies of HER. ${ }^{109}$ Also, some catalysts on the right-hand side of the volcano may be covered by amorphous oxides in HER conditions, which complicates the interpretation of the experiments. ${ }^{110}$ 
Strictly speaking, the activity of a catalyst in a reaction with $N$ intermediates has a multidimensional volcano-like dependency on $N$-binding energies, one for each involved species. For example, if the ORR mechanism is described by the simplified scheme,

$$
\frac{1}{2} \mathrm{O}_{2} \rightarrow \mathrm{O}^{*} \stackrel{+e^{-}+H^{+}}{\longrightarrow} \mathrm{OH}^{*} \stackrel{+e^{-}+H^{+}}{\longrightarrow} \mathrm{H}_{2} \mathrm{O},
$$

then the catalytic activity forms a two-dimensional (2D) volcano relationship with the binding energies of adsorbed $\mathrm{O}^{*}$ and $\mathrm{OH}^{*}$ species (see Figure $16 \mathrm{a},{ }^{98}$ note that spin unrestricted calculations may be necessary to describe the weakly binding side of the volcano in OER and $\left.\mathrm{ORR}^{111}\right)$. At the same time, the binding energies of $\mathrm{O}^{*}$ and $\mathrm{OH}^{*}$ were calculated to linearly correlate with each other, forming a so-called scaling relationship. ${ }^{19,20,112}$ Such correlations can be used to reduce an $\mathrm{N}$-dimensional volcano relationship into a straightforward one-dimensional (1D) volcano curve without significant loss of accuracy (Figure 16b). One-dimensional volcano curves are not only easy to visualize, they also simplify the rational design of new catalysts by decreasing the number of parameters to be optimized. 

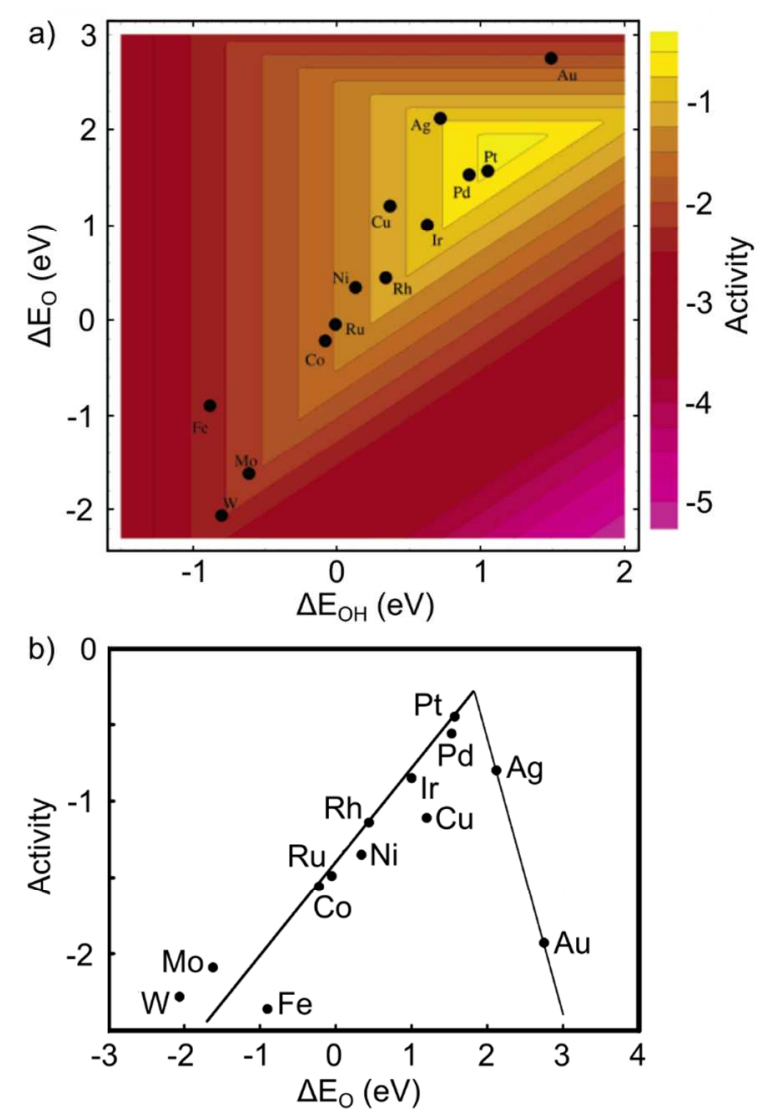

Figure 16. The volcano relationship between ORR activity and a) the binding energy of $O$ and $\mathrm{OH}$ to the catalyst, $\Delta \mathrm{E}_{\mathrm{O}}$ and $\Delta \mathrm{E}_{\mathrm{OH}}$, respectively, b) only the binding energy of $\mathrm{O}$. The latter volcano relies on the strong correlation between binding energies of $\mathrm{O}$ and $\mathrm{OH}$ on various catalysts. Adapted from Ref. 98.

On the other hand, the linear correlation between binding energies of various species to the catalyst surface may prevent engineering a catalyst that is located at the top of the volcano. Consequently, better ORR catalysts could be found among materials that do not follow the calculated scaling relationship between the binding energies of $\mathrm{O}$ and $\mathrm{OH} .{ }^{98}$ Finding such materials is a difficult task, as it requires completely changing the nature of the catalytic material. For example, although alloys of transition metals, such as Pt-Y discovered through volcano relationships in Ref. 113 may be more active than pure Pt in ORR, ultimately they follow the same scaling relationships between adsorption energies of $\mathrm{O}^{*}$ and $\mathrm{OH}^{*}$. Hence, alloys follow the same volcano relationship as pure transition metals and have the same theoretical limit 
of maximum activity. However, a broad set of oxides follows a different set of scaling

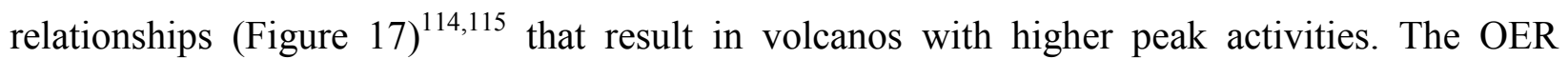
activities of $\mathrm{RuO}_{2},{ }^{116} \mathrm{SrCoO}_{3},{ }^{117}$ and Ni-doped $\alpha-\mathrm{Fe}_{2} \mathrm{O}_{3}{ }^{115}$ are calculated to exceed the suggested maximal activity of transition metals and alloys. Only oxyhydroxide OER catalysts may exhibit relatively weak correlation between $\mathrm{O}^{*}$ and $\mathrm{OH}^{*}$ binding energies. ${ }^{118}$ Doping $\mathrm{CoOOH}$ or $\mathrm{NiOOH}$ materials allowed to move from the line dictated by the scaling relationships and approach the peak of $2 \mathrm{D}$ volcano relationship for OER. ${ }^{118}$

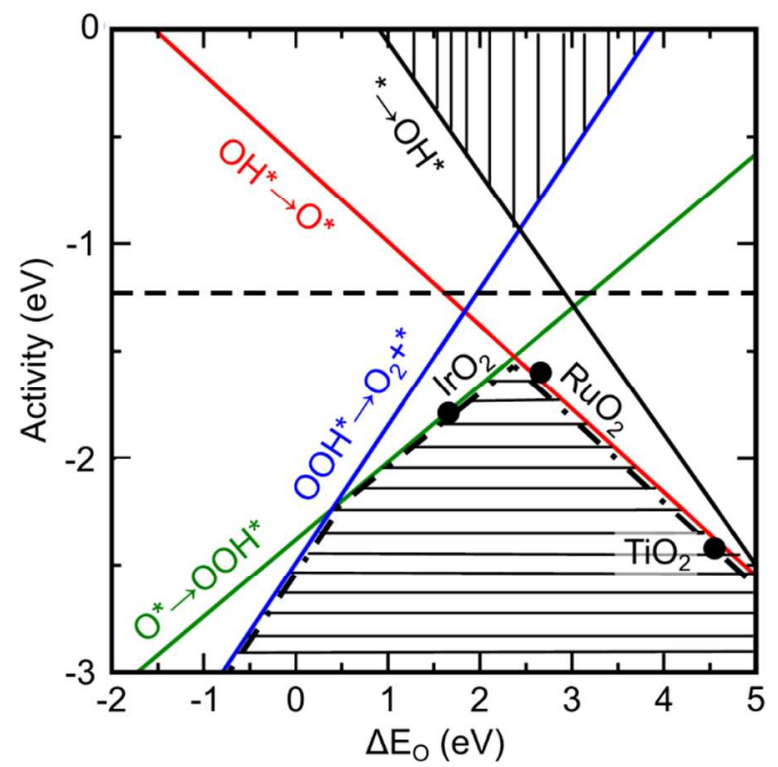

Figure 17. The volcano relationship between OER activity of various oxides and their O-binding energies. The horizontal dashed line at $-1.23 \mathrm{~V}$ indicates the maximum possible catalytic activity dictated by thermodynamic constraints. Adapted from Ref. 116 with permission from Elsevier.

Doped $\mathrm{RuO}_{2}$ is one of the few materials that that has been identified to be able to entirely escape the scaling relationships between binding energies of $\mathrm{OH}^{*}$ and $\mathrm{OOH}^{*}$, which bind to rutile $\mathrm{RuO}_{2}(110)$ surfaces in a different way. ${ }^{119}$ As a result, the OER activity of $\mathrm{RuO}_{2}$ doped by $\mathrm{Ni}$ and $\mathrm{Co}$ exceeds the maximum activity predicted by the simplified 1D volcano relationship and is closer to the peak of the multidimensional OER volcano. The increase in $\mathrm{RuO}_{2}$ activity in 
OER upon $\mathrm{Ni}$ and Co doping has also been confirmed experimentally. ${ }^{119}$ Identifying materials that break the scaling relationships between binding energies of key intermediates in a given reaction was proposed as a new paradigm for rational design of heterogeneous catalysts. ${ }^{120}$ For example, one could tune the pore size in a catalyst to alter the binding energies of larger intermediates, while maintaining the binding energies of smaller intermediates. ${ }^{121}$ However, the pore size that could change the relative binding strength of $\mathrm{OH}^{*}$ and $\mathrm{OOH}^{*}$ is calculated to be only $\sim 0.7 \mathrm{~nm}$ in $\mathrm{RuO}_{2}$, so a catalyst exploiting this effect may be difficult to engineer. ${ }^{122}$

The limitations imposed by the scaling relationships between binding energies of various intermediates are particularly severe for electrochemical reduction of $\mathrm{CO}_{2}\left(\mathrm{CO}_{2} \mathrm{RR}\right)$. This reaction is of pivotal importance to addressing environmental challenges and can also produce valuable methanol and $\mathrm{C}_{2}$ chemicals, as well as less valuable $\mathrm{CO}$ and $\mathrm{CH}_{4}{ }^{123}$ Despite many efforts, the best $\mathrm{CO}_{2} \mathrm{RR}$ catalysts often have overpotentials of $0.5-1.0 \mathrm{~V}$ for production of valuable hydrocarbons. ${ }^{124}$ According to the scaling relationships, the challenge in using $\mathrm{CO}_{2} \mathrm{RR}$ comes mostly from the following step,

$$
\mathrm{CO}^{*} \stackrel{+H^{+}+e^{-}}{\longrightarrow} \mathrm{COH}^{*}
$$

whose significant endothermicity is roughly the same for all transition metals. ${ }^{123}$ Because of many possible elementary steps, the volcano relationship between $\mathrm{CO}_{2} \mathrm{RR}$ activity and $\mathrm{CO}$ adsorption energy has an unusual convex feature in the region of strong CO binding (Figure 18). 


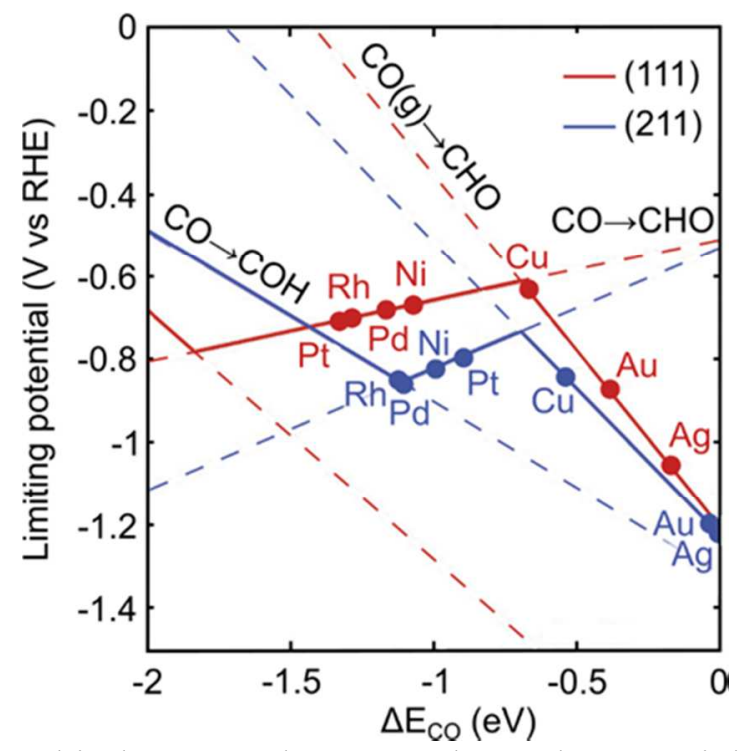

Figure 18. Volcano relationship between the onset electrode potential for $\mathrm{CO}_{2}$ reduction and the $\mathrm{CO}$ binding energy adapted from Ref. 125 with permission of the PCCP Owner Societies. Under certain conditions, the reaction rate is controlled by the fastest of two competing elementary steps, $\mathrm{CO}^{*} \rightarrow \mathrm{CHO}^{*}$ and $\mathrm{CO}^{*} \rightarrow \mathrm{COH}^{*}$, which leads to the convex feature in the strong $\mathrm{CO}$ binding region.

Typically the activity of a catalyst is determined by the slowest reaction step, which results in the regular concave shape of the volcano. However, at strong $\mathrm{CO}$ binding energies, the activity is determined by the faster of the two competing elementary steps,

$$
\begin{aligned}
& \mathrm{CO}^{*} \stackrel{+\mathrm{H}^{+}+e^{-}}{\longrightarrow} \mathrm{COH}^{*} \\
& \text { and } \\
& \mathrm{CO}^{*} \stackrel{+\mathrm{H}^{+}+e^{-}}{\longrightarrow} \mathrm{CHO}^{*},
\end{aligned}
$$

leading to the convex shape. Such strong CO binding energies are difficult to achieve experimentally; the observed volcano relationship based on experimental data does not exhibit a convex feature. $^{126}$

One of the pathways of methanol formation from $\mathrm{CO}_{2}$ proceeds only through intermediates that bind to the catalyst through $\mathrm{O}$ atoms. A volcano relationship was therefore found between the catalytic activity and O-binding energy, which led to the discovery of highly selective Ni-Ga 


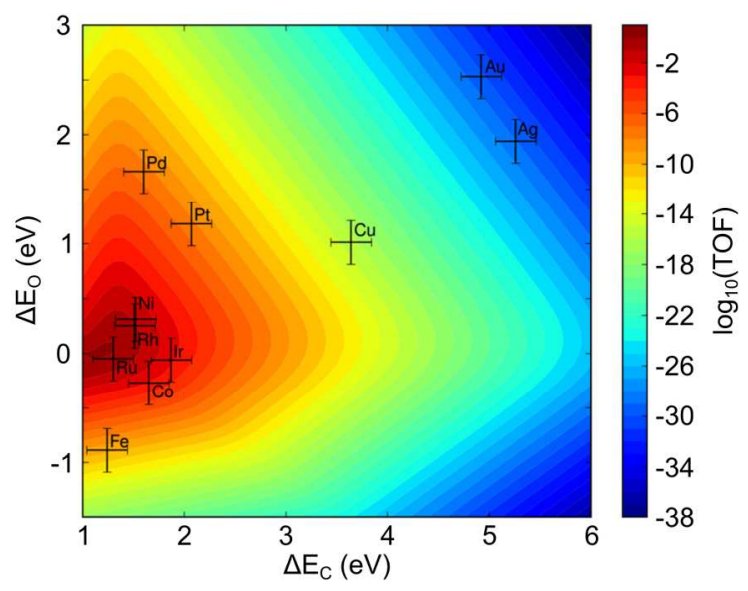


Figure 19. The volcano relationship between the TOF of a catalyst in methane steam reforming and binding energies of atomic $\mathrm{O}$ and $\mathrm{C}$ to the catalyst. Adapted from Ref. ${ }^{131}$ with permission from Elsevier.

The modern derivation of volcano relationships ${ }^{133}$ comes from the analysis of microkinetic models based on Brønsted-Evans-Polanyi relationships, i.e., on the handy ${ }^{134}$ assumption that activation energies of various elementary steps linearly correlate with their respective reaction energies. This analysis also revealed that the position of the peak of the volcano depends not only on the reaction temperature and pressure, but also on how close the reaction atmosphere is to the equilibrium between reactants and products. In principle, similar conclusions can be reached within the framework of ESM discussed earlier. ${ }^{24,44}$ In multistep reactions, the BrønstedEvans-Polanyi relationships can be combined with scaling relationships to devise a microkinetic model. This way of constructing volcano relationships was later validated through comparisons of calculated and experimental data for ORR activity of various transition metals and their alloys. ${ }^{135}$ Moreover, these volcano relationships were found to be similar to the much simpler "thermodynamic" volcanos based solely on the reaction energies of various elementary steps without taking kinetic barriers into account.

Occasionally, thermodynamic volcanos are also sufficient to analyze catalytic selectivity. Indeed, competing reaction pathways often exhibit different volcano relationships. Catalysts that fall closer to the peak of a particular volcano will be more selective towards the respective reaction. This approach was used to discover $\mathrm{Pt}-\mathrm{Hg}^{136}$ and later $\mathrm{Ag}-\mathrm{Hg}$ and $\mathrm{Pd}-\mathrm{Hg}$ catalysts ${ }^{137}$ for selective electrochemical $\mathrm{O}_{2}$ reduction to $\mathrm{H}_{2} \mathrm{O}_{2}$. Nevertheless, precise microkinetic models are indispensable in the reliable evaluations of catalytic selectivity in this reaction, since the selectivity may be extremely sensitive to the energy profile of the reaction. ${ }^{135}$ For example, in the study of volcano relationships and the selectivity of CO reduction on transition metals, a BEP 
microkinetic model containing $\sim 100$ elementary steps was employed ${ }^{138}$. In addition, a microkinetic model with more than 50 steps was used in a joint computational and experimental study aiming to optimize the composition of $\mathrm{Cu}-\mathrm{Co}$ alloys for higher selectivity of $\mathrm{CO}$ reduction to alcohols. ${ }^{139}$ Such studies are not only time consuming, they also critically depend on the accuracy of the chosen exchange-correlation functional. To avoid such complications, the volcano relationship of the catalytic activity and selectivity on the binding energies of various species could be inferred from chemical intuition. For instance, this approach was used to discover Ni-Zn catalysts for selective hydrogenation of acetylene to ethylene without further hydrogenation to ethane. ${ }^{140}$ Later Au-Ni catalysts were proposed for this reaction, since they are located close to the peak of the volcano for acetylene hydrogenation. ${ }^{141}$ At the same time, Au-Ni alloys were found to exhibit low ethylene binding energy, which prevents further hydrogenation.

Another recognized limitation of volcano relationships comes from the often neglected dependency of binding energies on the surface coverage of the considered or co-adsorbed species. ${ }^{133,135}$ Even in the simplest case of HER, the effect of $\mathrm{H}$ coverage on $\mathrm{H}$ binding energies and, hence, on the reaction kinetics may be significant. ${ }^{106}$ However, the importance of such interactions depends on the reaction. For example, these interactions do not seem to be crucial in formaldehyde synthesis from methanol. ${ }^{132}$ However, in the case of CO methanation, coadsorption interactions between key intermediates may change the reaction rate by several orders of magnitude but only when the catalysts become densely covered during the reaction. ${ }^{142}$ In addition, such interactions may cause the volcano relationship to be less steep, although they did not change the position of the volcano peak. In contrast, the presence of co-adsorbed $\mathrm{CO}$ during $\mathrm{CO}_{2}$ reduction affects the binding energies of $\mathrm{H}$ as well as other intermediates, thereby changing the optimal catalyst for HER and $\mathrm{CO}_{2} \mathrm{RR}^{125}$ 
Moreover, most electrochemical reactions occur in water, which may affect the binding energies of various species to the catalyst. For example, the energies of various intermediates in electrochemical $\mathrm{N}_{2}$ reduction were deliberately shifted by up to $0.2 \mathrm{eV}$ to account for the formation of H-bonds with surrounding water. ${ }^{130}$ Even larger corrections were suggested for the energies of $\mathrm{OH}^{*}$ and $\mathrm{OOH}^{*}$ intermediates in OER or ORR. ${ }^{98}$

As reported above, volcano plots are able to depict the full thermodynamic scenario involved in a catalytic cycle only the reactants, intermediates and products of the reaction are considered. On the other hand, in homogeneous catalysis, it is customary to describe catalytic activity based on an analysis of transition states. For this reason, although linear scaling relationships are well established in homogeneous catalysis, ${ }^{143-145}$ volcano plots for homogeneous catalysts were not reported until a few years ago. However, using cross-coupling as a model reaction (see Figure 20), Corminboeuf et al. showed that volcano plots can be useful in helping to identify thermodynamically good catalysts in homogenous reactions. ${ }^{146,147}$ 


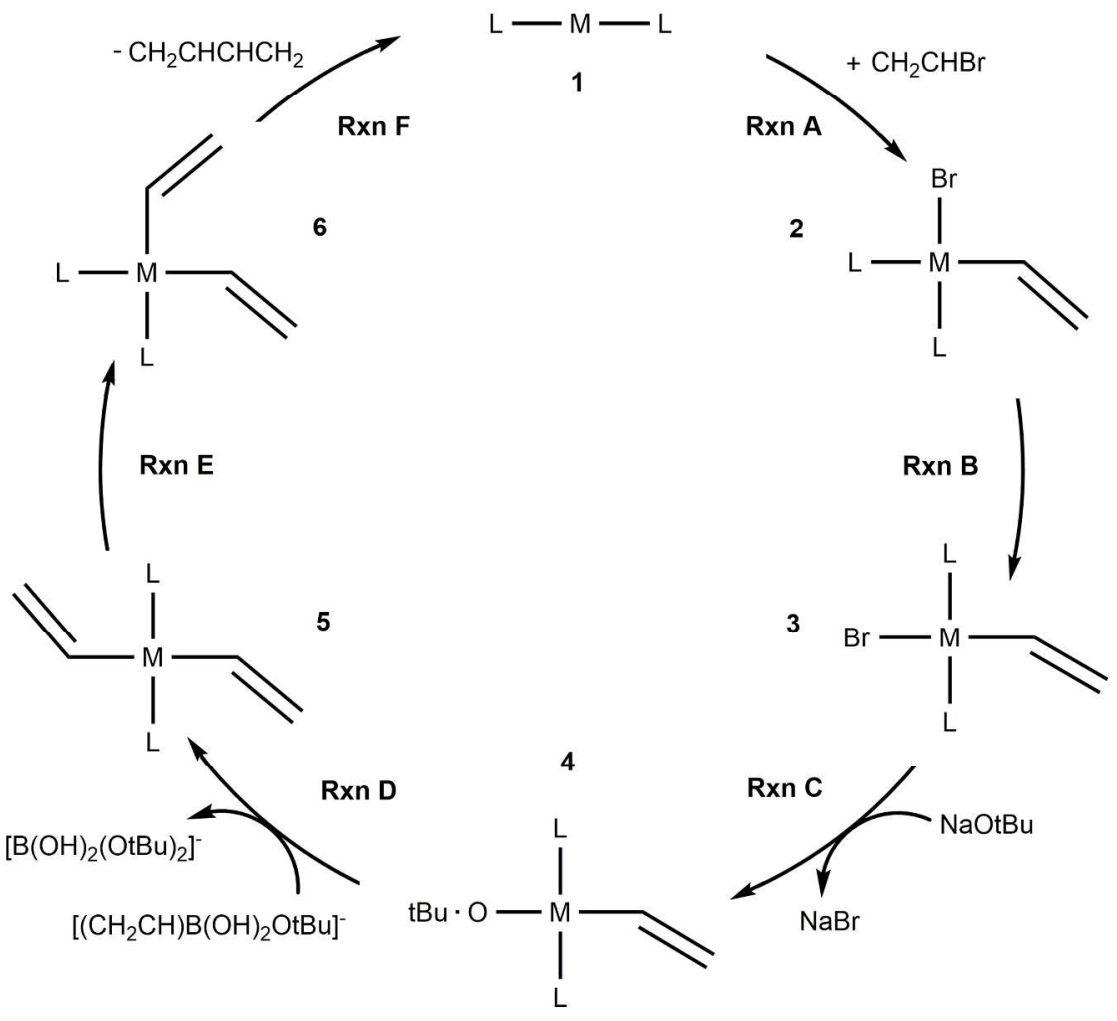

Figure 20. The reaction mechanism for the Suzuki cross-coupling of olefins. Reproduced with permission from Ref. 147.

They screened thirty-six potential systems consisting of various metals, including $\mathrm{Ni}, \mathrm{Pd}, \mathrm{Pt}$, $\mathrm{Cu}, \mathrm{Ag}, \mathrm{Au}$, and various ligands, including $\mathrm{CO}, \mathrm{NH}_{3}, \mathrm{PMe}_{3}$, acetone, and a $\mathrm{N}$-heterocyclic carbene. From the linear scaling relationships between the different species involved in the reaction, the energy of each intermediate was correlated with the energy of intermediate $\mathbf{3}$ (see Figure 20), chosen as the descriptor intermediate. A volcano relationship between the free energy of the "potential determining step", $\Delta G_{p d s}$, as determined by Eq. 10, and the free energy of the descriptor intermediate relative to the reactants, $\Delta G(3)$, was then constructed.

$$
\Delta G_{p d s}=\max [\Delta G(A), \Delta G(B), \Delta G(C), \Delta G(D), \Delta G(E), \Delta G(F)]
$$


(Eq. 10)

where $\Delta G(X)$ is the free energy of the $\mathrm{X}$ reaction step along the catalytic cycle. The obtained plot (Figure 21) allowed them to identify the potential determining steps in the catalytic cycle, namely reactions $\mathbf{A}, \mathbf{E}$ and $\mathbf{F}$.

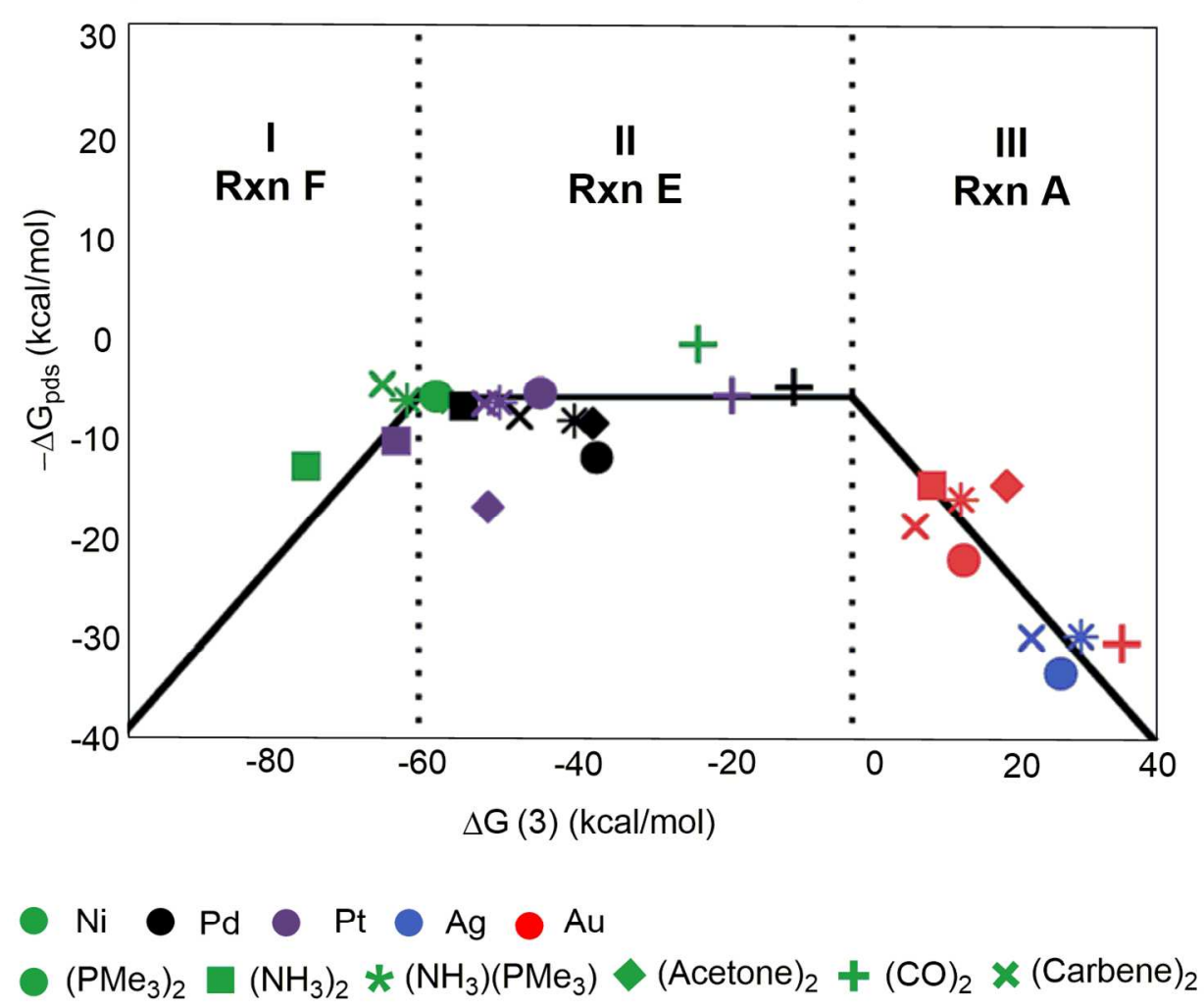

Figure 21. Volcano plot illustrating the thermodynamic scenario of the cross-coupling reaction. Adapted with permission from Ref. 147.

Catalysts leading to a very stable intermediate $\mathbf{3}$ in zone $\mathbf{I}$ of Figure 21 (strong binding in heterogeneous catalysis) undergo difficult reductive elimination (F); catalysts destabilizing intermediate 3 in zone III of Figure 21 (weak binding in heterogeneous catalysis) make the oxidative addition (A) potentially problematic. Finally, catalysts falling between in zone II of Figure 21 have the most appealing thermodynamic profile. Ni, Pd and Pt were found to be better 
catalysts in this reaction than $\mathrm{Ag}$ and $\mathrm{Au}$, which performed poorly during the $\mathrm{OA}$ step, in agreement with experimental observations. Moreover, the ligand effect is easily recognized and the results of ligand mixing or exchange can be predicted. For instance, it is clear that substitution of one $\mathrm{NH}_{3}$ with one $\mathrm{CO}$ in $\mathrm{Ni}$ catalysts (Figure 21, green points) can shift the catalyst to the central region, which improves the thermodynamic scenario.

This kind of volcano plot can easily help to screen potentially promising catalysts. For instance, it would be enough to calculate the energy of intermediate 3 relative to the reactants to predict the potential step that governs the activity of the newly screened catalysts. Once the energy of the species involved in the determining steps is calculated, the catalyst can be classified as promising or not.

Wodrich et al. ${ }^{148}$ extended this approach to predicting the kinetic profiles of homogeneous catalysts using kinetic volcano plots. They investigated the hydroformylation of ethylene and explored 32 catalysts with different metal (Fe, $\mathrm{Ru}, \mathrm{Os}, \mathrm{Co}, \mathrm{Rh}, \mathrm{Ir}, \mathrm{Ni}, \mathrm{Pt})$ or ligand $\left(\mathrm{PH}_{3}, \mathrm{PMe}_{3}\right.$, $\left.\mathrm{PPh}_{3}, \mathrm{PCy}_{3}\right)$ combinations. ${ }^{148}$ 


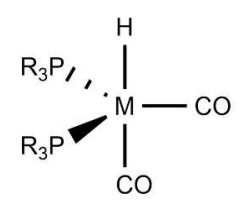

1

Figure 22. Mechanism for the hydroformylation of ethylene. Reproduced with permission from Ref.149.
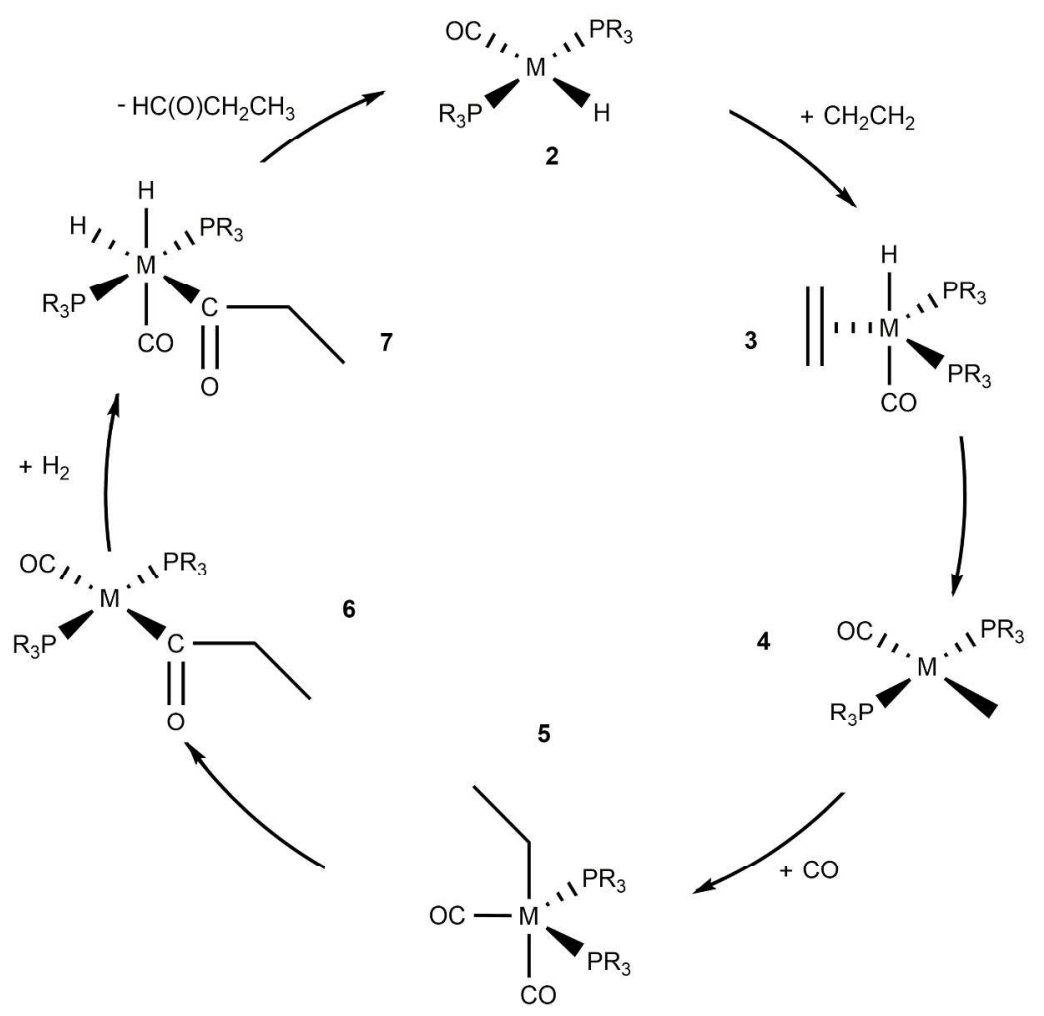

Scaling relationships describing the relative free energy of each catalytic cycle relative to the stability of a chosen intermediate as the descriptor, in this case intermediate $\mathbf{5}$ in Figure 22, were used to build a thermodynamic volcano plot ( $-\Delta G_{p d s}$ vs $\Delta G$ (5) as described above). In addition, the linear correlation between the energy of intermediate $\mathbf{5}$ and all transition states occurring in the catalytic cycle allowed them to build a kinetic volcano plot as well, where the yaxis is defined as the free energy of the kinetic determining step, $\Delta G_{k d s}^{\neq}$(see Eq. 11): 


$$
\Delta G_{k d s}^{\neq}=\max \left[\Delta G^{\neq}\left(3 \rightarrow T S_{3,4}\right), \Delta G^{\neq}\left(5 \rightarrow T S_{5,6}\right), \Delta G^{\neq}\left(6 \rightarrow T S_{6,7}\right), \Delta G^{\neq}\left(7 \rightarrow T S_{7,2}\right)\right]
$$

Analysis of the two plots in Figure 23 quickly allowed to identify the catalysts that will perform poorly. From a thermodynamic point of view, systems forming too stable intermediates (very negative $\Delta G(5)$ in Figure 23a) can have difficulty releasing the aldehyde product (step 7 to 2) or inserting the olefin into the $\mathrm{M}-\mathrm{H}$ bond to form an alkyl group (step 3 to 4). Similarly, the catalysts that destabilize the intermediates (very positive $\Delta G(5)$ in Figure 23a) will perform poorly due to difficulties in CO coordination (step 4 to 5). From a kinetic perspective, the plot in Figure 23b highlights olefin hydrogentation (step 3 to 4 ) and oxidative addition of $\mathrm{H}_{2}$ (step 6 to 7) as important to the reaction kinetics (very negative $-\Delta G_{p d s}$ in Figure $23 \mathrm{~b}$ ). The systems closer to the top of both volcano plots, i.e., those with good thermodynamic and kinetic profiles, clearly involve metals from group 9, while metals from groups 8 and 10 appear to perform worse. 


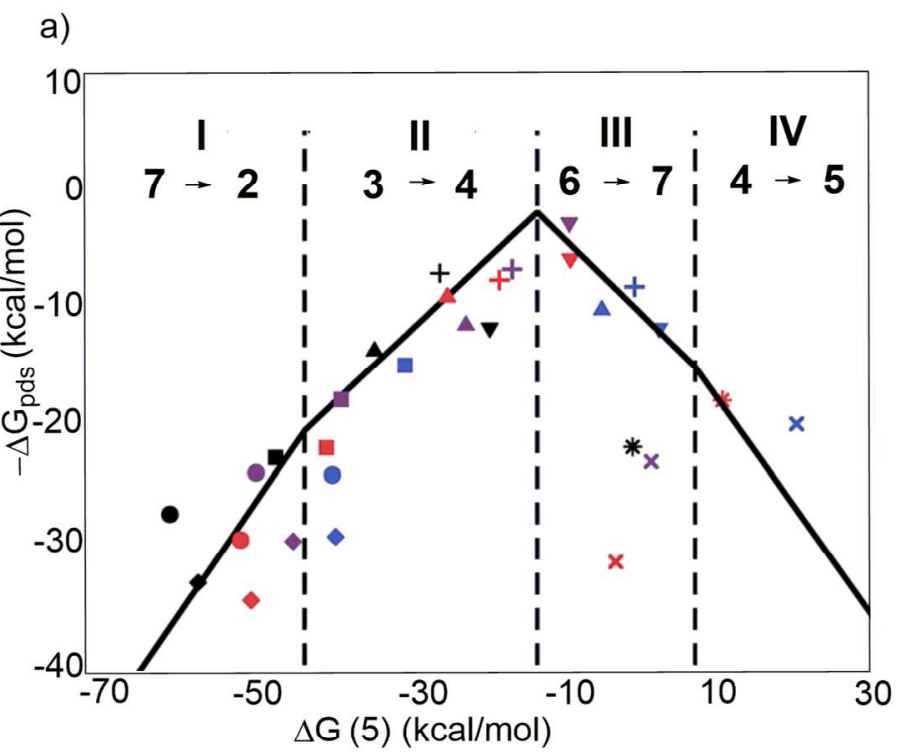

b)

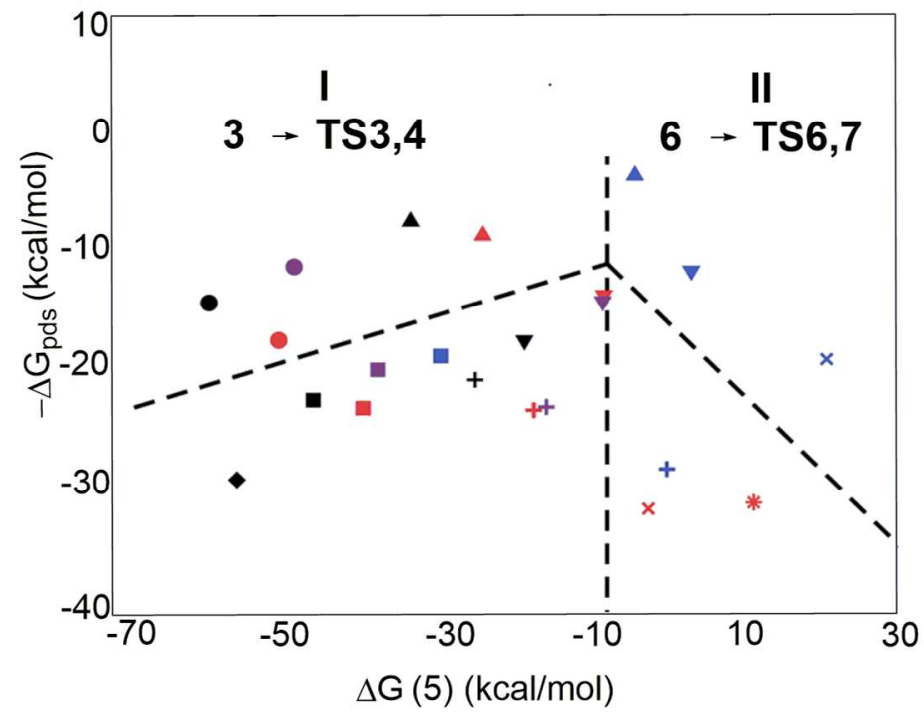

- $\mathrm{Fe} \boldsymbol{\nabla u} \bullet \mathrm{Os} \Delta \mathrm{Co} \nabla \mathrm{Rh}+\mathrm{Ir} \times \mathrm{Ni} * \mathrm{Pt}$

$\square \mathrm{PMe}_{3} \square \mathrm{PH}_{3} \square \mathrm{PPH}_{3} \square \mathrm{PCy}_{3}$

Figure 23. Volcano plots illustrating a) the thermodynamic scenario and b) the kinetic scenario for the hydroformylation reaction. Adapted with permission from Ref. 149.

Linear scaling relationships derived separately for each ligand showed that the steric hindrance of the ligand affects the last two transition states of the catalytic cycle. The height of the volcano increases with the steric hindrance of the phosphine ligand (see Figure 24), 
indicating that the kinetic determining energy barrier decreases when bulkier ligands are involved. This observation allowed the authors to correlate the kinetic determining energy barrier with a steric descriptor, such as the Tolman cone angle, and to estimate the activation barriers of various bulky catalysts without computationally expensive calculations to locate the transition state controlling the kinetics.

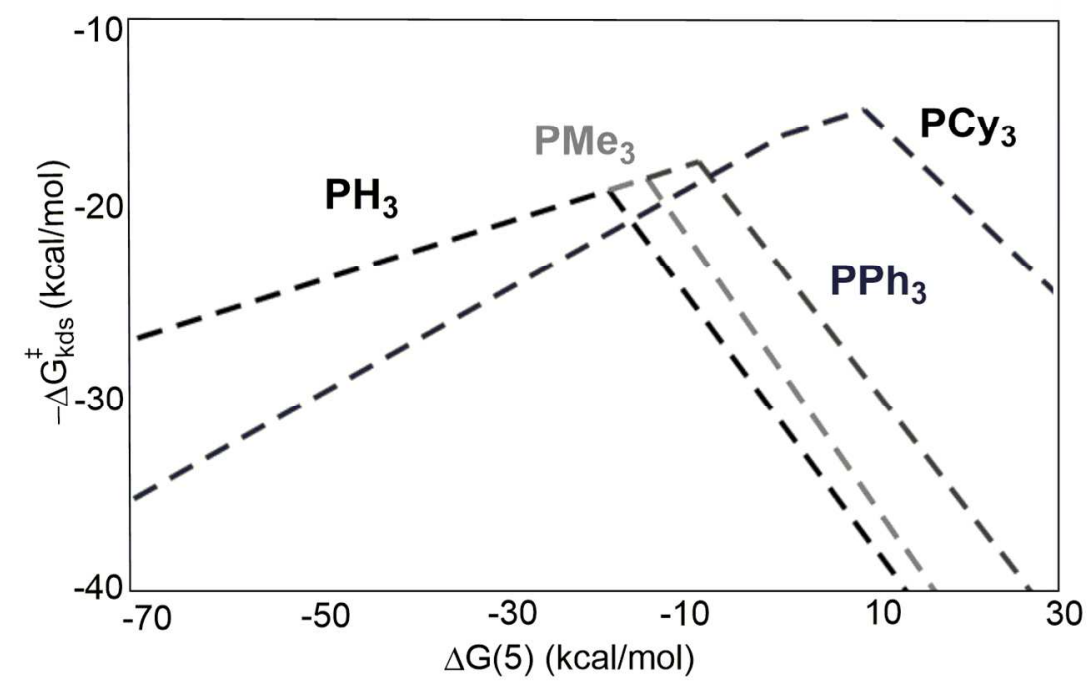

Figure 24. Kinetic volcano plots for the hydroformylation reaction separated by ligand type. Adapted with permission from Ref. 149.

\section{SUMMARY AND OUTLOOK}

Catalysis is a broad discipline historically divided into scarcely communicating subfields. Nevertheless, the fundamental principles of catalysis remain the same, whatever the nature of the specific catalyst under investigation. In this perspective we highlighted particular concepts (the energy span model, the energy decomposition analysis together with the activation strain model, and the volcano relationships) developed mostly within one specific subfield of catalysis, either heterogeneous or homogeneous, and that we think could help to frame and to analyze catalytic 
processes in the other subfield. We also highlighted niche applications of these concepts out of the original subfield.

Besides their potential as bridges connecting homogeneous and heterogeneous catalysis, we believe these tools may also serve as useful guides in the engineering of emerging classes of catalysts, such as metal-organic frameworks ${ }^{149}$ and size-selected clusters, which can be considered new subfields between homogeneous and heterogeneous catalysis. We believe that the wider application of such tools will push computational catalysis into a leading role in the discovery of new catalysts that address pressing environmental and sustainability concerns.

\section{AUTHOR INFORMATION \\ Corresponding authors \\ Email: sergey.kozlov@kaust.edu.sa, luigi.cavallo@kaust.edu.sa \\ ORCID:}

Laura Falivene: 0000-0003-1509-6191

Sergey M. Kozlov: 0000-0002-7765-4649

Luigi Cavallo: 0000-0002-1398-338X

Funding

Funding for this work was provided by King Abdullah University of Science and Technology (KAUST).

\section{Notes}

The authors declare no competing financial interest.

\section{REFERENCES}

(1) United Nations, Department of Economic and Social Affairs, P. D. World Population 
Prospects: The 2017 Revision, Key Findings and Advance Tables. ESA/P/WP/248.; 2017.

(2) Dahmen, S.; Bräse, S. Combinatorial Methods for the Discovery and Optimisation of

Homogeneous Catalysts. Synthesis (Stuttg). 2001, 10 (0), 1431-1449.

(3) Rajan, K. Combinatorial Materials Sciences: Experimental Strategies for Accelerated Knowledge Discovery. Annu. Rev. Mater. Res. 2008, 38 (1), 299-322.

(4) Sani, Y. M.; Daud, W. M. A. W.; Abdul Aziz, A. R. Activity of Solid Acid Catalysts for Biodiesel Production: A Critical Review. Appl. Catal. A Gen. 2014, 470, 140-161.

(5) Tong, L.; Thummel, R. P. Mononuclear Ruthenium Polypyridine Complexes That Catalyze Water Oxidation. Chem. Sci. 2016, 7 (11), 6591-6603.

(6) Costentin, C.; Robert, M.; Savéant, J. M. Current Issues in Molecular Catalysis Illustrated by Iron Porphyrins as Catalysts of the $\mathrm{CO}_{2}$-to-CO Electrochemical Conversion. Acc.

Chem. Res. 2015, 48 (12), 2996-3006.

(7) Baiker, A. Transition State Analogues - A Guide for the Rational Design of Enantioselective Heterogeneous Hydrogenation Catalysts. J. Mol. Catal. A Chem. 2000, $163(1-2), 205-220$.

(8) Stephen, A.; Hashmi, K. Homogeneous Gold Catalysis beyond Assumptions and Proposals-Characterized Intermediates. Angew. Chemie - Int. Ed. 2010, 49 (31), 52325241.

(9) Gascon, J.; Aktay, U.; Hernandez-Alonso, M. D.; van Klink, G. P. M.; Kapteijn, F. Amino-Based Metal-Organic Frameworks as Stable, Highly Active Basic Catalysts. J. Catal. 2009, 261 (1), 75-87.

(10) Gridnev, I. D.; Imamoto, T. On the Mechanism of Stereoselection in Rh-Catalyzed Asymmetric Hydrogenation: A General Approach for Predicting the Sense of 
Enantioselectivity. Acc. Chem. Res. 2004, 37 (9), 633-644.

(11) Hemelsoet, K.; Van Der Mynsbrugge, J.; De Wispelaere, K.; Waroquier, M.; Van

Speybroeck, V. Unraveling the Reaction Mechanisms Governing Methanol-to-Olefins

Catalysis by Theory and Experiment. ChemPhysChem 2013, 14 (8), 1526-1545.

(12) Nørskov, J. K.; Bligaard, T.; Rossmeisl, J.; Christensen, C. H. Towards the Computational Design of Solid Catalysts. Nat. Chem. 2009, 1 (1), 37-46.

(13) Wang, W.-H.; Hull, J. F.; Muckerman, J. T.; Fujita, E.; Himeda, Y. Second-CoordinationSphere and Electronic Effects Enhance Iridium(iii)-Catalyzed Homogeneous

Hydrogenation of Carbon Dioxide in Water near Ambient Temperature and Pressure. Energy Environ. Sci. 2012, 5 (7), 7923-7926.

(14) Tolman, C. A. Steric Effects of Phosphorus Ligands in Organometallic Chemistry and Homogeneous Catalysis. Chem. Rev. 1977, 77 (3), 313-348.

(15) Fukui, K.; Yonezawa, T.; Shingu, H. A Molecular Orbital Theory of Reactivity in Aromatic Hydrocarbons. J. Chem. Phys. 1952, 20, 722-725.

(16) Hoffman, R. Building Bridges Between Inorganic and Organic Chemistry. Angew. Chem. Int. Ed. Engl. 1982, 21, 711-724.

(17) Newns, D. M. Self-Consistent Model of Hydrogen Chemisorption. Phys. Rev. 1969, 178 (3), 1123-1135.

(18) Bligaard, T.; Nørskov, J. K. Ligand Effects in Heterogeneous Catalysis and Electrochemistry. Electrochim. Acta 2007, 52 (18), 5512-5516.

(19) Abild-Pedersen, F.; Greeley, J.; Studt, F.; Rossmeis1, J.; Munter, T. R.; Moses, P. G.; Skúlason, E.; Bligaard, T.; Nørskov, J. K. Scaling Properties of Adsorption Energies for Hydrogen-Containing Molecules on Transition-Metal Surfaces. Phys. Rev. Lett. 2007, 99, 
16105 .

(20) Montemore, M. M.; Medlin, J. W. Scaling Relations between Adsorption Energies for Computational Screening and Design of Catalysts. Catal. Sci. Technol. 2014, 4, 37483761.

(21) Morokuma, K. Molecular Orbital Studies of Hydrogen Bonds. III. C $=\mathrm{O} \cdots \mathrm{H}-\mathrm{O}$ Hydrogen Bond in $\mathrm{H}_{2} \mathrm{CO} \cdots \mathrm{H}_{2} \mathrm{O}$ and $\mathrm{H}_{2} \mathrm{CO} \cdots 2 \mathrm{H}_{2} \mathrm{O}$. J. Chem. Phys. 1971, 55 (3), 1236-1244.

(22) Ziegler, T.; Rauk, A. On the Calculation of Bonding Energies by Hartree-Fock Slater Method .1. Transition-State Method. Theor. Chim. Acta 1977, 46 (1), 1-10.

(23) Uhe, A.; Kozuch, S.; Shaik, S. Automatic Analysis of Computed Catalytic Cycles. J. Comput. Chem. 2011, 32 (5), 978-985.

(24) Kozuch, S.; Shaik, S. A Combined Kinetic-Quantum Mechanical Model for Assessment of Catalytic Cycles: Application to Cross-Coupling and Heck Reactions. J. Am. Chem. Soc. 2006, $128(10), 3355-3365$.

(25) Medford, A. J.; Vojvodic, A.; Hummelshøj, J. S.; Voss, J.; Abild-Pedersen, F.; Studt, F.; Bligaard, T.; Nilsson, A.; Nørskov, J. K. From the Sabatier Principle to a Predictive Theory of Transition-Metal Heterogeneous Catalysis. J. Catal. 2015, 328, 36-42.

(26) Seh, Z. W.; Kibsgaard, J.; Dickens, C. F.; Chorkendorff, I.; Nørskov, J. K.; Jaramillo, T. F. Combining Theory and Experiment in Electrocatalysis: Insights into Materials Design. Science 2017, 355 (6321), eaad4998.

(27) Christiansen, J. A. The Elucidation of Reaction Mechanisms by the Method of Intermediates in Quasi-Stationary Concentrations. Adv. Catal. 1953, 5 (C), 311-353.

(28) Amatore, C.; Jutand, A. Mechanistic and Kinetic Studies of Palladium Catalytic Systems. J. Organomet. Chem. 1999, 576 (1), 254-278. 
(29) Kozuch, S.; Shaik, S. How to Conceptualize Catalytic Cycles? The Energetic Span Model. Acc. Chem. Res. 2011, 44 (2), 101-110.

(30) Kozuch, S.; Amatore, C.; Jutand, A.; Shaik, S. What Makes for a Good Catalytic Cycle?

A Theoretical Study of the Role of an Anionic Palladium(0) Complex in the Cross-

Coupling of an Aryl Halide with an Anionic Nucleophile. Organometallics 2005, 24 (10), 2319-2330.

(31) Kozuch, S.; Lee, S. E.; Shaik, S. Theoretical Analysis of the Catalytic Cycle of a Nickel Cross-Coupling Process: Application of the Energetic Span Model. Organometallics 2009, $28(5), 1303-1308$.

(32) Kozuch, S.; Martin, J. M. L. What Makes for a Good Catalytic Cycle? A Theoretical Study of the SPhos Ligand in the Suzuki-Miyaura Reaction. Chem. Commun. 2011, 47 (17), 4935-4937.

(33) Dudle, B.; Rajesh, K.; Blacque, O.; Berke, H. Rhenium in Homogeneous Catalysis: [ReBrH(NO)(labile Ligand)(large-Bite-Angle Diphosphine)] Complexes as Highly Active Catalysts in Olefin Hydrogenations. J. Am. Chem. Soc. 2011, 133 (21), 8168-8178.

(34) Geilen, F. M. A.; Engendahl, B.; Hölscher, M.; Klankermayer, J.; Leitner, W. Selective Homogeneous Hydrogenation of Biogenic Carboxylic Acids with [Ru(TriPhos)H]+: A Mechanistic Study. J. Am. Chem. Soc. 2011, 133 (36), 14349-14358.

(35) Kefalidis, C. E.; Tsipis, C. A. DFT Study of the Mechanism of Hydroamination of Ethylene with Ammonia Catalyzed by diplatinum(II) Complexes: Inner- or Outer-Sphere? J. Comput. Chem. 2012, 33 (20), 1689-1700.

(36) Yu, Z.-X.; Cheong, P. H.-Y.; Liu, P.; Legault, C. Y.; Wender, P. A.; Houk, K. N. Origins of Differences in Reactivities of Alkenes, Alkynes, and Allenes in $\left[\mathrm{Rh}(\mathrm{CO})_{2} \mathrm{Cl}\right]^{2-}$ 
Catalyzed $(5+2)$ Cycloaddition Reactions with Vinylcyclopropanes. J. Am. Chem. Soc. 2008, $130(8), 2378-2379$.

(37) Nuñez-Zarur, F.; Solans-Monfort, X.; Rodríguez-Santiago, L.; Pleixats, R.; Sodupe, M. Mechanistic Insights into Ring-Closing Enyne Metathesis with the Second-Generation Grubbs-Hoveyda Catalyst: A DFT Study. Chem. - A Eur. J. 2011, 17 (27), 7506-7520.

(38) Poater, A.; Solans-Monfort, X.; Clot, E.; Copéret, C.; Eisenstein, O. Understanding d0Olefin Metathesis Catalysts: Which Metal, Which Ligands? J. Am. Chem. Soc. 2007, 129 (26), 8207-8216.

(39) Barder, T. E.; Walker, S. D.; Martinelli, J. R.; Buchwald, S. L. Catalysts for Suzuki-Miyaura Coupling Processes: Scope and Studies of the Effect of Ligand Structure. J. Am. Chem. Soc. 2005, 127 (13), 4685-4696.

(40) Kozuch, S.; Martin, J. M. L. What Makes for a Bad Catalytic Cycle? A Theoretical Study on the Suzuki-Miyaura Reaction within the Energetic Span Model. ACS Catal. 2011, 1 (4), 246-253.

(41) Campbell, C. T. Future Directions and Industrial Perspectives Micro- and Macro-Kinetics: Their Relationship in Heterogeneous Catalysis. Top. Catal. 1994, 1 (3-4), 353-366.

(42) Hewage, D.; Silva, W. R.; Cao, W.; Yang, D. S. La-Activated Bicyclo-Oligomerization of Acetylene to Naphthalene. J. Am. Chem. Soc. 2016, 138 (8), 2468-2471.

(43) Wang, W.; Wang, G.-C. Computational Study on the Mechanism and Enantioselectivity of $\mathrm{Rh}_{2}(\mathrm{~S} \text {-PTAD })_{4}$ Catalyzed Asymmetric [4+3] Cycloaddition between Vinylcarbenoids and Dienes. RSC Adv. 2015, 5 (101), 83459-83470.

(44) Kozuch, S.; Shaik, S. Kinetic-Quantum Chemical Model for Catalytic Cycles: The HaberBosch Process and the Effect of Reagent Concentration. J. Phys. Chem. A 2008, 112, 
$6032-6041$.

(45) Zhdanov, V. P.; Kasemo, B. Kinetic Phase Transitions in Simple Reactions on Solid Surfaces. Surf. Sci. Rep. 1994, 20 (3), 113-189.

(46) Ertl, G. Reactions at Surfaces: From Atoms to Complexity (Nobel Lecture). Angew. Chemie - Int. Ed. 2008, 47 (19), 3524-3535.

(47) Kozuch, S. A Refinement of Everyday Thinking: The Energetic Span Model for Kinetic Assessment of Catalytic Cycles. Wiley Interdiscip. Rev. Comput. Mol. Sci. 2012, 2 (5), $795-815$.

(48) Boudart, M. Turnover Rates in Heterogeneous Catalysis. Chem. Rev. 1995, 95 (3), 661666.

(49) Huang, X.; Hou, X.; Zhao, J.; Zhang, L. Hematite Facet Confined Ferrous Ions as High Efficient Fenton Catalysts to Degrade Organic Contaminants by Lowering $\mathrm{H}_{2} \mathrm{O}_{2}$

Decomposition Energetic Span. Appl. Catal. B Environ. 2016, 181, 127-137.

(50) Nian, J.; Wang, Y.; Ma, W.; Ji, D.; Wang, C.; La, M. Theoretical Investigation for the Cycle Reaction of $\mathrm{N}_{2} \mathrm{O}\left(\mathrm{x}^{1} \Sigma^{+}\right)$with $\mathrm{CO}\left({ }^{1} \Sigma^{+}\right)$Catalyzed by $\mathrm{IrO}_{n}{ }^{+}(n=1,2)$ and Utilizing the Energy Span Model to Study Its Kinetic Information. J. Phys. Chem. A 2011, 115 (40), $11023-11032$.

(51) Cao, Z.; Guo, L.; Liu, N. A Theoretical Study of the Water-gas-Shift Reaction on $\mathrm{Cu}_{6} \mathrm{TM}$ $(\mathrm{TM}=\mathrm{Co}, \mathrm{Ni}, \mathrm{Cu}, \mathrm{Rh}, \mathrm{Pd}, \mathrm{Ag}, \mathrm{Ir}, \mathrm{Pt}, \mathrm{Au})$ Clusters. J. Clust. Sci. 2016, 27 (2), 523-535.

(52) Brogaard, R. Y.; Olsbye, U. Ethene Oligomerization in Ni-Containing Zeolites:

Theoretical Discrimination of Reaction Mechanisms. ACS Catal. 2016, 6 (2), 1205-1214.

(53) Wang, S.; Vorotnikov, V.; Vlachos, D. G. Coverage-Induced Conformational Effects on Activity and Selectivity: Hydrogenation and Decarbonylation of Furfural on $\operatorname{Pd}(111) . A C S$ 
Catal. 2015, 5 (1), 104-112.

(54) Guan, J.; Li, J.; Yu, Y.; Mu, X.; Chen, A. DFT Studies of the Selective C-O

Hydrogenolysis and Ring-Opening of Biomass-Derived Tetrahydrofurfuryl Alcohol over Rh(111) Surfaces. J. Phys. Chem. C 2016, 120 (34), 19124-19134.

(55) Wang, S. G.; Liao, X. Y.; Hu, J.; Cao, D. B.; Li, Y. W.; Wang, J.; Jiao, H. Kinetic Aspect of $\mathrm{CO}_{2}$ Reforming of $\mathrm{CH}_{4}$ on $\mathrm{Ni}\left(\begin{array}{lll}1 & 1 & 1\end{array}\right)$ : A Density Functional Theory Calculation. Surf. Sci. 2007, 601 (5), 1271-1284.

(56) Graciani, J.; Mudiyanselage, K.; Xu, F.; Baber, A. E.; Evans, J.; Senanayake, S. D.; Stacchiola, D. J.; Liu, P.; Hrbek, J.; Sanz, J. F.; et al. Highly Active Copper-Ceria and Copper-Ceria-Titania Catalysts for Methanol Synthesis from $\mathrm{CO}_{2}$. Science 2014, 345 (6196), 546-550.

(57) Hoffmann, R.; Woodward, R. B. Orbital Symmetry Control of Chemical Reactions. Science 1970, 167 (3919), 825-831.

(58) Woodward, R. B.; Hoffmann, R. Stereochemistry of Electrocyclic Reactions. J. Am. Chem. Soc. 1965, 87 (2), 395-397.

(59) Fukui, K. Recognition of Stereochemical Paths by Orbital Interaction. Acc. Chem. Res. 1971, 4 (2), 57-64.

(60) Marcus, R. A. Chemical and Electrochemical Electron-Transfer Theory. Annu. Rev. Phys. Chem. 1964, 15 (1), 155.

(61) Nagase, S.; Morokuma, K. An Ab Initio Molecular Orbital Study of Organic Reactions. The Energy, Charge, and Spin Decomposition Analyses at the Transition State and along the Reaction Pathway. J. Am. Chem. Soc. 1978, 100 (6), 1666-1672.

(62) Houk, K. N.; Ruth, W. G.; Strozier, R. W.; Rondan, N. G.; Paquette, L. A. On the Barriers 
to Thermally Allowed Reactions and the Elusiveness of Neutral Homoaromaticity. J. Am. Chem. Soc. 1979, 101 (23), 6797-6802.

(63) Bickelhaupt, F. M.; Nibbering, N. M. M.; Baerends, E. J.; Ziegler, T. Theoretical Investigation on Base-Induced 1,2-Eliminations in the Model System F- $+\mathrm{CH}_{3} \mathrm{CH}_{2} \mathrm{~F}$. The Role of the Base as a Catalyst. J. Am. Chem. Soc. 1993, 115 (20), 9160-9173.

(64) van Zeist, W.-J.; Bickelhaupt, F. M. The Activation Strain Model of Chemical Reactivity. Org. Biomol. Chem. 2010, 8 (14), 3118-3127.

(65) Fernández, I.; Bickelhaupt, F. M. The Activation Strain Model and Molecular Orbital Theory: Understanding and Designing Chemical Reactions. Chem. Soc. Rev. 2014, 43 (14), 4953-4967.

(66) Wolters, L. P.; Bickelhaupt, F. M. The Activation Strain Model and Molecular Orbital Theory. Wiley Interdiscip. Rev. Comput. Mol. Sci. 2015, 5 (4), 324-343.

(67) Fernández, I.; Cossío, F. P. Interplay between Aromaticity and Strain in Double Group Transfer Reactions to 1,2-Benzyne. J. Comput. Chem. 2016, 37 (14), 1265-1273.

(68) Shinisha, C. B.; Sunoj, R. B. Transition State Models for Probing Stereoinduction in Evans Chiral Auxiliary-Based Asymmetric Aldol Reactions. J. Am. Chem. Soc. 2010, 132 (35), 12319-12330.

(69) Levandowski, B. J.; Hamlin, T. A.; Bickelhaupt, F. M.; Houk, K. N. Role of Orbital Interactions and Activation Strain (Distortion Energies) on Reactivities in the Normal and Inverse Electron-Demand Cycloadditions of Strained and Unstrained Cycloalkenes. $J$. Org. Chem. 2017, 82 (16), 8668-8675.

(70) De Jong, G. T.; Bickelhaupt, F. M. Transition-State Energy and Position along the Reaction Coordinate in an Extended Activation Strain Model. ChemPhysChem 2007, 8 
(8), 1170-1181.

(71) Diefenbach, A.; De Jong, G. T.; Bickelhaupt, F. M. Activation of H-H, C-H, C-C and CCl Bonds by Pd and PdCl-. Understanding Anion Assistance in C-X Bond Activation. $J$. Chem. Theory Comput. 2005, 1 (2), 286-298.

(72) De Jong, G. T.; Bickelhaupt, F. M. Catalytic Carbon-Halogen Bond Activation: Trends in Reactivity, Selectivity, and Solvation. J. Chem. Theory Comput. 2007, 3 (2), 514-529.

(73) Kubelka, J.; Bickelhaupt, F. M. Activation Strain Analysis of $\mathrm{S}_{\mathrm{N}} 2$ Reactions at C, N, O, and F Centers. J. Phys. Chem. A 2017, 121 (4), 885-891.

(74) Bräse, S.; Meijere, A. De. Cross-Coupling of Organyl Halides with Alkenes: The Heck Reaction. In Metal-Catalyzed Cross-Coupling Reactions; Wiley-VCH Verlag GmbH, 2004; pp 217-315.

(75) Fernández, I.; Wolters, L. P.; Bickelhaupt, F. M. Controlling the Oxidative Addition of Aryl Halides to Au(I). J. Comput. Chem. 2014, 35 (29), 2140-2145.

(76) Estrada, J.; Lee, S. E.; McArthur, S. G.; El-Hellani, A.; Tham, F. S.; Lavallo, V. Resisting B-H Oxidative Addition: The Divergent Reactivity of the O-Carborane and Carba-ClosoDodecaborate Ligand Substituents. J. Organomet. Chem. 2015, 798, 214-217.

(77) Joost, M.; Zeineddine, A.; Estévez, L.; Mallet-Ladeira, S.; Miqueu, K.; Amgoune, A.; Bourissou, D. Facile Oxidative Addition of Aryl Iodides to Gold(I) by Ligand Design: Bending Turns on Reactivity. J. Am. Chem. Soc. 2014, 136 (42), 14654-14657.

(78) Faza, O. N.; López, C. S.; Fernández, I. Noyori Hydrogenation: Aromaticity, Synchronicity, and Activation Strain Analysis. J. Org. Chem. 2013, 78 (11), 5669-5676.

(79) Aleksandrov, H. A.; Kozlov, S. M.; Vayssilov, G. N.; Neyman, K. M. Approaching Complexity of Alkyl Hydrogenation on Pd via Density-Functional Modelling. Phys. 
Chem. Chem. Phys. 2017, 19 (32), 21514-21521.

(80) Morin, C.; Simon, D.; Sautet, P. Density-Functional Study of the Adsorption and Vibration Spectra of Benzene Molecules on Pt(111). J. Phys. Chem. B 2003, 107 (13), 2995-3002.

(81) Morin, C.; Simon, D.; Sautet, P. Chemisorption of Benzene on Pt(111), Pd(111), and Rh(111) Metal Surfaces: A Structural and Vibrational Comparison from First Principles. J. Phys. Chem. B 2004, 108 (18), 5653-5665.

(82) Morin, C.; Simon, D.; Sautet, P. Intermediates in the Hydrogenation of Benzene to Cyclohexene on Pt(111) and Pd(111): A Comparison from DFT Calculations. Surf. Sci. 2006, $600(6), 1339-1350$.

(83) Essen, J. M.; Haubrich, J.; Becker, C.; Wandelt, K. Adsorption of Ethene on Pt(1 111$)$ and Ordered $\mathrm{Pt}_{\mathrm{x}} \mathrm{Sn} / \mathrm{Pt}\left(\begin{array}{lll}1 & 1 & 1\end{array}\right)$ Surface Alloys: A Comparative HREELS and DFT Investigation. Surf. Sci. 2007, 601, 3472-3480.

(84) Becker, C.; Haubrich, J.; Wandelt, K.; Loffreda, D.; Sautet, P. Adsorption of Simple Alkenes on Pt (111) and Pt - Sn Surface Alloys : Bond Strength versus Heat of Adsorption. 2008, 112, 14693-14695.

(85) Yang, M. L.; Zhu, Y. A.; Zhou, X. G.; Sui, Z. J.; Chen, D. First-Principles Calculations of Propane Dehydrogenation over PtSn Catalysts. ACS Catal. 2012, 2 (6), 1247-1258.

(86) Hammer, B.; Nørskov, J. K. Theoretical Surface Science and Catalysis - calculations and Concepts. Adv. Catal. 2000, 45 (C), 71-129.

(87) Basaran, D.; Aleksandrov, H. A.; Chen, Z. X.; Zhao, Z. J.; Rösch, N. Decomposition of Ethylene on Transition Metal Surfaces M(l 111$)$. A Comparative DFT Study of Model Reactions for M = Pd, Pt, Rh, Ni. J. Mol. Catal. A Chem. 2011, 344 (1-2), 37-46. 
(88) Bockris, J. O. Electrolytic polarisation-I. The Overpotential of Hydrogen on Some Less Common Metals at High Current Densities. Influence of Current Density and Time.

Trans. Faraday Soc. 1947, 43, 417-429.

(89) Conway, B. E.; Bockris, J. O. Electrolytic Hydrogen Evolution Kinetics and Its Relation to the Electronic and Adsorptive Properties of the Metal. J. Chem. Phys. 1957, 26 (3), $532-541$.

(90) Horiuti, J.; Polanyi, M. Acta. Physicochim. U.R.S.S. 1935, 2, 505-532.

(91) Horiuti, J.; Polanyi, M. Outlines of a Theory of Proton Transfer. J. Mol. Catal. A Chem. 2003, $199(1-2), 185-197$.

(92) Parsons, R. The Rate of Electrolytic Hydrogen Evolution and the Heat of Adsorption of Hydrogen. Trans. Faraday Soc. 1958, 54, 1053-1063.

(93) Trasatti, S. Work Function, Electronegativity, and Electrochemical Behaviour of Metals. III. Electrolytic Hydrogen Evolution in Acid Solutions. J. Electroanal. Chem. 1972, 39 (1), 163-184.

(94) Trasatti, S. Electrocatalysis by oxides-Attempt at a Unifying Approach. J Electroanal Chem 1980, $111(1), 125-131$.

(95) Appleby, A. J. Electrocatalysis of Aqueous Dioxygen Reduction. J. Electroanal. Chem. 1993, $357(1-2), 117-179$.

(96) Mukerjee, S.; Srinivasan, S.; Soriaga, M. P.; McBreen, J. Role of Structural and Electronic Properties of Pt and Pt Alloys on Electrocatalysis of Oxygen Reduction. J. Electrochem. Soc. 1995, 142 (5), 1409-1422.

(97) Toda, T.; Igarashi, H.; Uchida, H.; Watanabe, M. Enhancement of the Electroreduction of Oxygen on Pt Alloys with Fe, Ni, and Co. J. Electrochem. Soc. 1999, 146 (10), 3750- 
3756.

(98) Nørskov, J. K.; Rossmeisl, J.; Logadottir, A.; Lindqvist, L.; Kitchin, J. R.; Bligaard, T.;

Jónsson, H. Origin of the Overpotential for Oxygen Reduction at a Fuel-Cell Cathode. $J$. Phys. Chem. B 2004, 108 (46), 17886-17892.

(99) Stamenkovic, V. R.; Mun, B. S.; Arenz, M.; Mayrhofer, K. J. J.; Lucas, C. A.; Wang, G.; Ross, P. N.; Markovic, N. M. Trends in Electrocatalysis on Extended and Nanoscale PtBimetallic Alloy Surfaces. Nat. Mater. 2007, 6 (3), 241-247.

(100) Suntivich, J.; Gasteiger, H. A.; Yabuuchi, N.; Nakanishi, H.; Goodenough, J. B.; ShaoHorn, Y. Design Principles for Oxygen-Reduction Activity on Perovskite Oxide Catalysts for Fuel Cells and Metal-air Batteries. Nat. Chem. 2011, 3 (8), 546-550.

(101) Campbell, C. T. Finding the Rate-Determining Step in a Mechanism. J. Catal. 2001, 204 (2), 520-524.

(102) Wolcott, C. A.; Medford, A. J.; Studt, F.; Campbell, C. T. Degree of Rate Control Approach to Computational Catalyst Screening. J. Catal. 2015, 330, 197-207.

(103) Jacobsen, C. J. H.; Dahl, S.; Clausen, B. G. S.; Bahn, S.; Logadottir, A.; Nørskov, J. K. Catalyst Design by Interpolation in the Periodic Table: Bimetallic Ammonia Synthesis Catalysts. J. Am. Chem. Soc. 2001, 123 (34), 8404-8405.

(104) Andersson, M. P.; Bligaard, T.; Kustov, A.; Larsen, K. E.; Greeley, J.; Johannessen, T.; Christensen, C. H.; Nørskov, J. K. Toward Computational Screening in Heterogeneous Catalysis: Pareto-Optimal Methanation Catalysts. J. Catal. 2006, 239, 501-506.

(105) Greeley, J.; Jaramillo, T. F.; Bonde, J.; Chorkendorff, I.; Nørskov, J. K. Computational High-Throughput Screening of Electrocatalytic Materials for Hydrogen Evolution. Nat. Mater. 2006, 5 (11), 909-913. 
(106) Nørskov, J. K.; Bligaard, T.; Logadottir, A.; Kitchin, J. R.; Chen, J. G.; Pandelov, S.; Stimming, U. Trends in the Exchange Current for Hydrogen Evolution. J. Electrochem. Soc. 2005, 152 (3), J23-J26.

(107) Kibsgaard, J.; Tsai, C.; Chan, K.; Benck, J. D.; Nørskov, J. K.; Abild-Pedersen, F.; Jaramillo, T. F. Designing an Improved Transition Metal Phosphide Catalyst for Hydrogen Evolution Using Experimental and Theoretical Trends. Energy Environ. Sci. 2015, 8 (10), 3022-3029.

(108) Hinnemann, B.; Moses, P. G.; Bonde, J.; Jørgensen, K. P.; Nielsen, J. H.; Horch, S.; Chorkendorff, I.; Nørskov, J. K. Biomimetic Hydrogen Evolution: MoS2 Nanoparticles as Catalyst for Hydrogen Evolution. J. Am. Chem. Soc. 2005, 127 (15), 5308-5309.

(109) Skulason, E.; Tripkovic, V.; Bjorketun, M. E.; Gudmundsdottir, S.; Karlberg, G.; Rossmeis1, J.; Bligaard, T.; Jonsson, H.; Nørskov, J. K. Modeling the Electrochemical Hydrogen Oxidation and Evolution Reactions on the Basis of Density Functional Theory Calculations. J. Phys. Chem. C 2010, 114, 18182-18197.

(110) Quaino, P.; Juarez, F.; Santos, E.; Schmickler, W. Volcano Plots in Hydrogen Electrocatalysis - Uses and Abuses. Beilstein J. Nanotechnol. 2014, 5, 846-854.

(111) Mom, R. V.; Cheng, J.; Koper, M. T. M.; Sprik, M. Modeling the Oxygen Evolution Reaction on Metal Oxides: The Infuence of Unrestricted DFT Calculations. J. Phys. Chem. C 2014, 118 (8), 4095-4102.

(112) Calle-Vallejo, F.; Loffreda, D.; Koper, M. T. M.; Sautet, P. Introducing Structural Sensitivity into Adsorption-energy Scaling Relations by Means of Coordination Numbers. Nat. Chem. 2015, 7 (5), 403-410.

(113) Greeley, J.; Stephens, I. E. L.; Bondarenko, A. S.; Johansson, T. P.; Hansen, H. A.; 
Jaramillo, T. F.; Rossmeisl, J.; Chorkendorff, I.; Nørskov, J. K. Alloys of Platinum and Early Transition Metals as Oxygen Reduction Electrocatalysts. Nat. Chem. 2009, 1 (7), $552-556$.

(114) Tedsree, K.; Li, T.; Jones, S.; Chan, C. W. A.; Yu, K. M. K.; Bagot, P. A. J.; Marquis, E. A.; Smith, G. D. W.; Tsang, S. C. E. Hydrogen Production from Formic Acid Decomposition at Room Temperature Using a Ag-Pd Core-Shell Nanocatalyst. Nat. Nanotechnol. 2011, 6 (5), 302-307.

(115) Liao, P.; Keith, J. A.; Carter, E. A. Water Oxidation on Pure and Doped Hematite (0001) Surfaces: Prediction of Co and Ni as Effective Dopants for Electrocatalysis. J. Am. Chem. Soc. 2012, 134 (32), 13296-13309.

(116) Rossmeisl, J.; Qu, Z. W.; Zhu, H.; Kroes, G. J.; Nørskov, J. K. Electrolysis of Water on Oxide Surfaces. J. Electroanal. Chem. 2007, 607 (1-2), 83-89.

(117) Man, I. C.; Su, H. Y.; Calle-Vallejo, F.; Hansen, H. A.; Martínez, J. I.; Inoglu, N. G.; Kitchin, J.; Jaramillo, T. F.; Nørskov, J. K.; Rossmeisl, J. Universality in Oxygen Evolution Electrocatalysis on Oxide Surfaces. ChemCatChem 2011, 3 (7), 1159-1165.

(118) Bajdich, M.; García-Mota, M.; Vojvodic, A.; Nørskov, J. K.; Bell, A. T. Theoretical Investigation of the Activity of Cobalt Oxides for the Electrochemical Oxidation of Water. J. Am. Chem. Soc. 2013, 135 (36), 13521-13530.

(119) Halck, N. B.; Petrykin, V.; Krtil, P.; Rossmeisl, J. Beyond the Volcano Limitations in Electrocatalysis - Oxygen Evolution Reaction. Phys. Chem. Chem. Phys. 2014, 16 (27), $13682-13688$.

(120) Vojvodic, A.; Nørskov, J. K. New Design Paradigm for Heterogeneous Catalysts. Natl. Sci. Rev. 2015, 2 (October), 140-149. 
(121) Abild-Pedersen, F. Computational Catalyst Screening: Scaling, Bond-Order and Catalysis. Catal. Today 2016, 272, 6-13.

(122) Doyle, A. D.; Montoya, J. H.; Vojvodic, A. Improving Oxygen Electrochemistry through Nanoscopic Confinement. ChemCatChem 2015, 7 (5), 738-742.

(123) Peterson, A. A.; Nørskov, J. K. Activity Descriptors for $\mathrm{CO}_{2}$ Electroreduction to Methane on Transition-Metal Catalysts. J. Phys. Chem. Lett. 2012, 3 (2), 251-258.

(124) Qiao, J.; Liu, Y.; Hong, F.; Zhang, J. A Review of Catalysts for the Electroreduction of Carbon Dioxide to Produce Low-Carbon Fuels. Chem. Soc. Rev. Chem. Soc. Rev 2014, 43 (43), 631-675.

(125) Shi, C.; Hansen, H. A.; Lausche, A. C.; Nørskov, J. K. Trends in Electrochemical $\mathrm{CO}_{2}$ Reduction Activity for Open and Close-Packed Metal Surfaces. Phys. Chem. Chem. Phys. 2014, $16(10), 4720-4727$.

(126) Kuhl, K. P.; Hatsukade, T.; Cave, E. R.; Abram, D. N.; Kibsgaard, J.; Jaramillo, T. F. Electrocatalytic Conversion of Carbon Dioxide to Methane and Methanol on Transition Metal Surfaces. J. Am. Chem. Soc. 2014, 136 (40), 14107-14113.

(127) Studt, F.; Sharafutdinov, I.; Abild-Pedersen, F.; Elkjær, C. F.; Hummelshøj, J. S.; Dahl, S.; Chorkendorff, I.; Nørskov, J. K. Discovery of a Ni-Ga Catalyst for Carbon Dioxide Reduction to Methanol. Nat. Chem. 2014, 6 (4), 320-324.

(128) Kunkel, C.; Viñes, F.; Illas, F. Transition Metal Carbides as Novel Materials for $\mathrm{CO}_{2}$ Capture, Storage, and Activation. Energy Environ. Sci. 2016, 9 (1), 141-144.

(129) Michalsky, R.; Zhang, Y. J.; Medford, A. J.; Peterson, A. A. Departures from the Adsorption Energy Scaling Relations for Metal Carbide Catalysts. J. Phys. Chem. C 2014, $118(24), 13026-13034$. 
(130) Skúlason, E.; Bligaard, T.; Gudmundsdóttir, S.; Studt, F.; Rossmeisl, J.; Abild-Pedersen, F.; Vegge, T.; Jónsson, H.; Nørskov, J. K. A Theoretical Evaluation of Possible Transition Metal Electro-Catalysts for $\mathrm{N}_{2}$ Reduction. Phys. Chem. Chem. Phys. 2012, 14 (3), 12351245.

(131) Jones, G.; Jakobsen, J. G.; Shim, S. S.; Kleis, J.; Andersson, M. P.; Rossmeisl, J.; AbildPedersen, F.; Bligaard, T.; Helveg, S.; Hinnemann, B.; et al. First Principles Calculations and Experimental Insight into Methane Steam Reforming over Transition Metal Catalysts. J. Catal. 2008, 259 (1), 147-160.

(132) Li, H. J.; Lausche, A. C.; Peterson, A. A.; Hansen, H. A.; Studt, F.; Bligaard, T. Using Microkinetic Analysis to Search for Novel Anhydrous Formaldehyde Production Catalysts. Surf. Sci. 2015, 641, 105-111.

(133) Bligaard, T.; Nørskov, J. K.; Dahl, S.; Matthiesen, J.; Christensen, C. H.; Sehested, J. The Brønsted-Evans-Polanyi Relation and the Volcano Curve in Heterogeneous Catalysis. $J$. Catal. 2004, 224 (1), 206-217.

(134) Hummelshøj, J. S.; Abild-Pedersen, F.; Studt, F.; Bligaard, T.; Nørskov, J. K. CatApp: A Web Application for Surface Chemistry and Heterogeneous Catalysis. Angew. Chemie Int. Ed. 2012, 51 (1), 272-274.

(135) Hansen, H. A.; Viswanathan, V.; Nørskov, J. K. Unifying Kinetic and Thermodynamic Analysis of $2 \mathrm{e}^{-}$and $4 \mathrm{e}^{-}$Reduction of Oxygen on Metal Surfaces. J. Phys. Chem. C 2014, $118(13), 6706-6718$.

(136) Siahrostami, S.; Verdaguer-Casadevall, A.; Karamad, M.; Deiana, D.; Malacrida, P.; Wickman, B.; Escudero-Escribano, M.; Paoli, E. A.; Frydendal, R.; Hansen, T. W.; et al. Enabling Direct $\mathrm{H}_{2} \mathrm{O}_{2}$ Production through Rational Electrocatalyst Design. Nat. Mater. 
2013, 12 (12), 1137-1143.

(137) Verdaguer-Casadevall, A.; Deiana, D.; Karamad, M.; Siahrostami, S.; Malacrida, P.; Hansen, T. W.; Rossmeisl, J.; Chorkendorff, I.; Stephens, I. E. L. Trends in the Electrochemical Synthesis of $\mathrm{H}_{2} \mathrm{O}_{2}$ : Enhancing Activity and Selectivity by Electrocatalytic Site Engineering. Nano Lett. 2014, 14 (3), 1603-1608.

(138) Medford, A. J.; Lausche, A. C.; Abild-Pedersen, F.; Temel, B.; Schjødt, N. C.; Nørskov, J. K.; Studt, F. Activity and Selectivity Trends in Synthesis Gas Conversion to Higher Alcohols. Top. Catal. 2014, 57 (1-4), 135-142.

(139) Prieto, G.; Beijer, S.; Smith, M. L.; He, M.; Au, Y.; Wang, Z.; Bruce, D. A.; De Jong, K. P.; Spivey, J. J.; De Jongh, P. E. Design and Synthesis of Copper-Cobalt Catalysts for the Selective Conversion of Synthesis Gas to Ethanol and Higher Alcohols. Angew. Chemie Int. Ed. 2014, 53 (25), 6397-6401.

(140) Studt, F.; Abild-Pedersen, F.; Bligaard, T.; Sørensen, R. Z.; Christensen, C. H.; Nørskov, J. K. Identification of Non-Precious Metal Alloy Catalysts for Selective Hydrogenation of Acetylene. Science 2008, 320 (January), 1320-1322.

(141) Yang, B.; Burch, R.; Hardacre, C.; Headdock, G.; Hu, P. Origin of the Increase of Activity and Selectivity of Nickel Doped by $\mathrm{Au}, \mathrm{Ag}$, and $\mathrm{Cu}$ for Acetylene Hydrogenation. ACS Catal. 2012, 2 (6), 1027-1032.

(142) Lausche, A. C.; Medford, A. J.; Khan, T. S.; Xu, Y.; Bligaard, T.; Abild-Pedersen, F.; Nørskov, J. K.; Studt, F. On the Effect of Coverage-Dependent Adsorbate-Adsorbate Interactions for CO Methanation on Transition Metal Surfaces. J. Catal. 2013, 307, 275282.

(143) Hammett, L. P. Effect of Structure upon the Reactions of Organic Compounds. Benzene 
Derivatives. J. Am. Chem. Soc. 1937, 59 (1936), 96-103.

(144) Wang, Y.; Montoya, J. H.; Tsai, C.; Ahlquist, M. S. G.; Nørskov, J. K.; Studt, F. Scaling Relationships for Binding Energies of Transition Metal Complexes. Catal. Letters 2016, $146(2), 304-308$.

(145) Audran, G.; Brémond, P.; Marque, S. R. A.; Siri, D.; Santelli, M. Calculated Linear Free Energy Relationships in the Course of the Suzuki-Miyaura Coupling Reaction.

Tetrahedron 2014, 70, 2272-2279.

(146) Busch, M.; Wodrich, M. D.; Corminboeuf, C. Linear Scaling Relationships and Volcano Plots in Homogeneous Catalysis - Revisiting the Suzuki Reaction. Chem. Sci. 2015, 6 (12), 6754-6761.

(147) Busch, M.; Wodrich, M. D.; Corminboeuf, C. A Generalized Picture of C-C CrossCoupling. ACS Catal. 2017, 7 (9), 5643-5653.

(148) Wodrich, M. D.; Busch, M.; Corminboeuf, C. Chemical Science Homogeneous Catalysts from Volcano Plots. Chem. Sci. 2016, 7, 5723-5735.

(149) Liu, J.; Chen, L.; Cui, H.; Zhang, J.; Zhang, L.; Su, C.-Y. Applications of Metal-organic Frameworks in Heterogeneous Supramolecular Catalysis. Chem. Soc. Rev. 2014, 43 (16), 6011-6061. 


\section{Table of Contents}

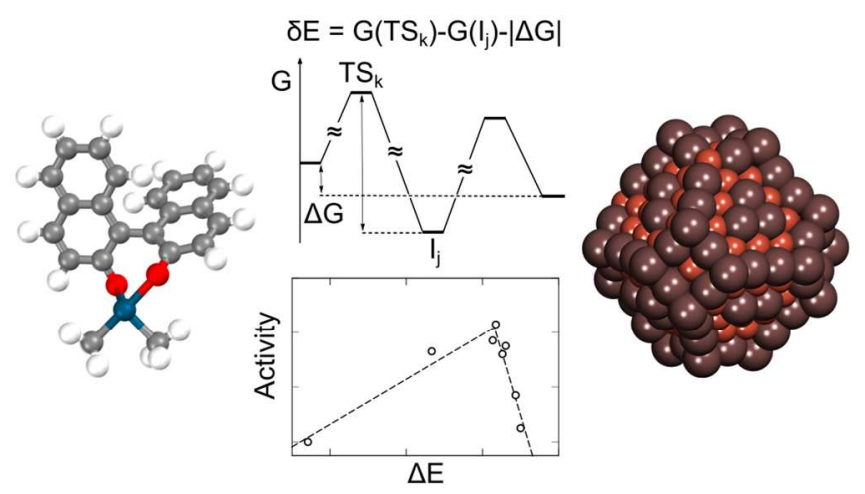

